\title{
Article
}

\section{Rapid prediction of seismic incident angle's influence on the damage level of RC buildings using Artificial Neural Networks}

\author{
Konstantinos Morfidis ${ }^{1, *}$, Konstantinos Kostinakis ${ }^{2}$ \\ 1 Earthquake Planning and Protection Organization (EPPO-ITSAK), Terma Dasylliou, 55535 Thessaloniki, \\ Greece \\ 2 Department of Civil Engineering, Aristotle University of Thessaloniki, Aristotle University Campus, 54124 \\ Thessaloniki, Greece; kkostina@civil.auth.gr [K.K] \\ * Correspondence: konmorf@gmail.com [K.M]
}

\begin{abstract}
The angle of seismic excitation is a significant factor of the seismic response of RC buildings. The procedure required for the calculation of the angle for which the potential seismic damage is maximized (critical angle) contains multiple nonlinear time history analyses using in each one of them different angles of incidence. Moreover, the seismic codes recommend the application of more than one accelerograms for the evaluation of seismic response. Thus, the whole procedure becomes time consuming. Herein, a method to reduce the time required for the estimation of the critical angle based on Multilayered Feedforward Perceptron Neural Networks is proposed. The basic idea is the detection of cases in which the critical angle increases the class of seismic damage compared to the class which arises from the application of the seismic motion along the buildings' structural axes. To this end, the problem is expressed and solved as Pattern Recognition problem. As inputs of networks the ratios of seismic parameters' values along the two horizontal seismic records' components, as well as appropriately chosen structural parameters, were used. The results of analyses show that the neural networks can reliably detect the cases in which the calculation of the critical angle is essential.
\end{abstract}

Keywords: artificial neural networks; pattern recognition; reinforced concrete buildings; seismic damage; rapid assessment; seismic incident angle

\section{Introduction}

The angle of seismic excitation has been recognized by the civil engineering research community as a significant factor of the seismic response of RC buildings since many years ago. The level of the influence of this angle to the seismic response was proved in several published research studies. Among the research papers which deal with this subject some of the most significant are the following: MacRae and Mattheis [1] examined the impact of angle of incidence on the inelastic response of a three-story steel frame building due to near-fault ground motions. Athanatopoulou [2] has introduced analytical formulae for the determination of the critical incident angle and the corresponding maximum elastic structural response of buildings subjected to three correlated seismic components. The application of these formulae to multistory structures has proved that the maximum value of a response quantity can be up to $180 \%$ larger than the response produced when the seismic accelerograms act along the structural axes. In another study, Rigato and Medina [3] investigated the inelastic response of asymmetric and symmetric buildings with regard to the angle of incidence by using 39 pairs of ground motion records. The results showed that the critical angle for a given response quantity depends on fundamental period, model type and level of inelastic behavior and it is difficult to be 
determined a priori, as in case of elastic structures. In a series of research studies conducted by Kostinakis et al. [4-7] and Fontara et al. [8] the influence of the seismic motion's orientation on the elastic and inelastic seismic behaviour of RC structures was investigated. They found that the structural response is strongly dependent on the strong motion's direction. Pavel and Nica [9] investigated the seismic behaviour of doubly symmetric RC wall structures subjected to a series of bi-directional ground motion recordings. They revealed that the structural response is dependent on the orientation of the strong ground motion horizontal components. Cavdar and Ozdemir [10] examined the change in response of a seismically isolated structure as a function of ground motion orientation and they showed that using the maximum direction of ground motions does not lead to the maximum response compared to the one obtained by considering different orientations of seismic records. The issue of the seismic motion's orientation from a probabilistic point of view was also investigated by a number of researchers (Lagaros [11]; Giannopoulos and Vamvatsikos [12]; Vargas et al. [13]; Skoulidou et al. [14]; Skoulidou and Romão [15]), who tried to evaluate the impact of the angle of seismic incidence on the buildings' risk.

The angle of seismic excitation is defined as the angle which is formed by the orientation of the seismic input and the structural axes of buildings. In common practice, the considered orientation of the seismic input coincides to the structural axes. However, as mentioned in the above literature review, it was proved that the most unfavorable seismic response arises generally for different angle which is referred as the critical angle of the seismic excitation. The procedure for the estimation of the critical angle requires the performance of multiple analyses. In each one of these analyses the angle of seismic input is increased from zero (which corresponds to the orientation of the structural axes of buildings) to 360 degrees through an increment which is usually taken equal to 5 degrees. If the evaluation of the seismic response concerns the prediction of the potential seismic damage Nonlinear Time History Analyses (NTHA) are required. Thus, for the estimation of the critical angle a series of NTHA must be performed. Moreover, the modern seismic codes (i.e. [16]) recommend the evaluation of the seismic response of buildings using more than one earthquake records. Obviously, each one of the selected seismic motions can lead to a different critical angle, following the application of the above-mentioned procedure. Therefore, the whole procedure requires the implementation of a number of sets of NTHA. Each one of these sets includes, beyond the stage of analyses, the stage of the post-processing of the extracted results for the estimation of the selected seismic damage index. Thus, the ability to avoid the procedure for the estimation of the critical angle for a seismic record is desirable. In order to achieve this, an available computational tool is the Artificial Neural Networks (ANNs).

The implementation of ANNs for the solution of civil engineering problems is progressively increased during the last three decades. This fact is reflected to several published review papers [17-21]. Concentrating on the seismic assessment of RC buildings, among the plenty of papers which deal with the application of ANNs, it is worth to mention some of them. Firstly, it is necessary to mention the research studies of Stephens and VanLuchene [22] and Molas and Yamazaki [23] as the first systematic attempts to use properly trained ANNs in order to predict rapidly the level of seismic damage of structures. De Stefano et al. [24] studied successfully the ability of probabilistic neural networks for the prediction of the mechanisms of seismic damage of monumental buildings. Sanchez-Silva and Garcia [25] examined the efficiency of combined performance of multilayered feed-forward neural networks and fuzzy logic theory for the earthquake damage assessment of structures using data extracted from in situ surveys after a strong earthquake. Feed-forward neural networks were implemented efficiently by Lagaros and Fragiadakis [26] for the fragility assessment of steel frames. Gonzalez and Zapico [27] successfully tested the ability of multi-layered perceptron networks for the reliable identification of the seismic damage of multi-storey welded steel moment frame buildings. Lautour and Omenzetter [28] proved that the multi-layered perceptron networks have 
the ability to predict reliably the seismic damage of 2D RC buildings. Arslan [29] investigated the effect of several structural parameters on the seismic performance of regular RC buildings using multi-layered perceptron networks trained with data which were created artificially, and proved the effectiveness of ANNs in the reliable prediction of the structures' seismic response. Vafaei et al. [30] studied successfully the performance of multi-layered perceptron networks in the real-time identification of earthquake-induced damage of RC shear walls. Morfidis and Kostinakis [31-33] examined the performance of the multi-layered perceptron networks and the Radial-Basis Function networks in the rapid estimation of the seismic damage level using regression as well as pattern recognition approach and they extracted very promising results.

In the present paper, the effective implementation of Multi-Layered Perceptron (MLP) networks for the rapid prediction of influence of seismic incident angle on the RC buildings' Seismic Damage Level (SDL) is examined. The basic idea is the application of MLP networks for the prediction of the cases in which the critical angle has a strong (or not strong) influence on the potential SDL of RC buildings. Predicting reliably the level of influence of the critical angle on the SDL for an RC building at the stage of design, the abovementioned time-consuming procedure for the estimation of this influence can be avoided. The same is valid in case of the seismic vulnerability assessment of existing RC buildings. The problem was formulated and solved as Pattern Recognition (PR) problem [34]. Thus, the seismic damage was expressed by means of pre-defined Seismic Damage Classes (SDC) and the MLP networks were used to predict if the critical angle alters a building's SDC in comparison with the SDC in which the building is classified when the angle of seismic excitation is considered as equal to zero i.e. the case in which the angle of seismic excitation coincides with the structural axes of the building. Additionally, the MLP networks were used to predict the specific SDC in which a RC building is classified when the critical angle is considered. In the above-mentioned approaches three seismic damage classes were pre-defined, namely slight, medium and heavy on the basis of the selected Seismic Damage Index (SDI). The selected SDI was the Maximum Interstorey Drift Ratio (MIDR) which is used in several research papers (see e.g. [35,36]). For the training of the MLP networks three data-sets were used: one data-set which is based on analyses of RC buildings without masonry infills (Bare Buildings, BB), one data-set which is based on analyses of RC buildings with masonry infills (Regularly Infilled Buildings, RIB) and one data-set which is based on analyses of RC buildings with masonry infills in all stories except of the ground storey (Irregularly Infilled Buildings, IIB). The full description of these three data-sets as well as the corresponding procedure for their generation is presented in [32,33]. An extended investigation for the estimation of the optimum configuration of the MLP networks, i.e. the configuration which leads to the most reliable prediction of the influence of incident angle was performed for all above-mentioned approaches of the problem. Also, it must be noted that the procedure proposed in the present study gives the ability to optimize the configuration of RC buildings at the stage of design by testing several alternative configurations (without the requirement for implementation of numerus time-consuming NTHA) and select the one which leads to seismic response slightly influenced by the angle of seismic excitation. The results of the current research led to the basic conclusion that the MLP networks can reliably predict in real time the level of influence of the critical angle of seismic excitation on the seismic damage of RC buildings.

\section{Short theoretical background}

A short theoretical background of the scientific fields which are involved in the present paper are presented in the current section. At first, some of the fundamentals which describe the problem of estimation of the critical incident angle for RC buildings are given in sub-section 2.1. Afterwards, some of the basic principles which concern the implementation of MLP networks for the solution of PR problems are presented in sub-section 2.2. 


\subsection{The influence of incident angle on the seismic response of $R C$ buildings}

In the vast majority of earthquake records' databases, the horizontal components of the seismic motion are given along the orientation they were recorded for. Thus, the orientation of the recorded seismic components is predetermined by the orientation of the recording instrument (accelerograph), which is, in general, arbitrary with respect to the structural axes of the buildings (Figure 1), (Beyer and Bommer [37]). In Figure 1 let $\alpha_{\times}(t) \kappa \alpha \iota \alpha_{y}(t)$ represent the recorded earthquake acceleration time histories at the place of the accelerograph along its axes $x$ and $y$ respectively. These accelerograms can be applied along any angle of incidence $\theta$ between the seismic components and the building's structural axes $X$ and $Y\left(a_{x}(\theta)\right.$ and $\left.a_{y}(\theta)\right)$.

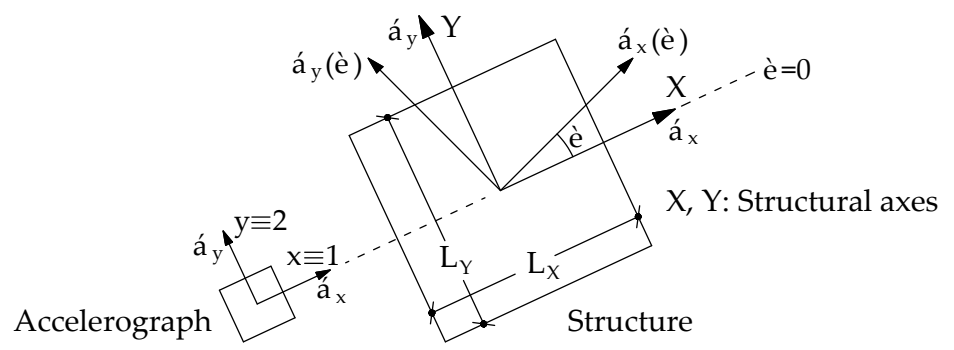

Figure 1. Recorded ground motion and orientation of building structural axes

The seismic response of any structure is dependent on the orientation of the strong motion with regard to the structural axes. It is of great importance to notice that the rotation of the axes along which the horizontal accelerograms are applied can lead to completely different structural behaviour.

The orientation of the earthquake record has not caught till now the attention of the most modern seismic codes. Specifically, EN1998-2 [38] does not make any reference to this issue and, according to FEMA 356 [39], ASCE 41-06 [40] and ASCE 41-13 [41], the axes of the ground motion "shall, in general, be aligned with the principal axes of the structure." EN1998-1 [16], states that the seismic action shall "be applied along all relevant horizontal directions.". Nevertheless, no specifications are made concerning the relevant horizontal directions with the exception of buildings with resisting elements in two perpendicular directions in which these two directions shall be considered as the relevant ones. NZS (Code and Supplement of the New Zealand Standard) [42] states that the seismic accelerograms are applied along the direction that will lead to the most unfavorable value of the considered response parameter, without specifying, however, how the most critical direction should be determined.

The lack of specific code provisions with regard to the axes of the strong motion input leads to the application of the horizontal earthquake components along the structural axes of the buildings. This common engineering practice can result in significant underestimation of seismic demands (Athanatopoulou [2]; Rigato and Medina [3]; Kostinakis et al. [4-7]; Fontara et al. [8]; Pavel and Nica [9]; Cavdar and Ozdemir [10]; Skoulidou et al. [14]; Lucchini et al. [43]; Nguyen and Kim [44]; Roy et al. [45]).

\subsection{The solution of the PR problem using MLP networks}

The Pattern Recognition (PR) problem is one of the subjects of the Machine Learning (ML) algorithms (see e.g. [34,46]). The inherent ability of MLP networks to solve problems which are characterized by high nonlinearity make them capable to solve effectively PR problems. By definition, PR is the procedure of the search for specific patterns in data-sets. Between the three different general types of PR problems (i.e. supervised learning problems, unsupervised learning problems and reinforcement learning problems), the present paper deals with a supervised learning problem. In the framework of a supervised learning PR problem, the ML algorithm attempts to classify correctly the samples of 
a data-set to pre-defined classes which are defined by properly selected ranges of values of pre-selected parameters. This problem is called classification problem. In present paper, the pre-defined classes are the SDC, and the parameter which is used for the definition of them is the SDI (detailed presentation of these definitions is given in section 3).

As regards the solution of the PR problem in its classification form using MLP networks, a proper configuration for them is required. In Figure 2 the general form of an MLP network configured for the solution of a classification problem is presented.

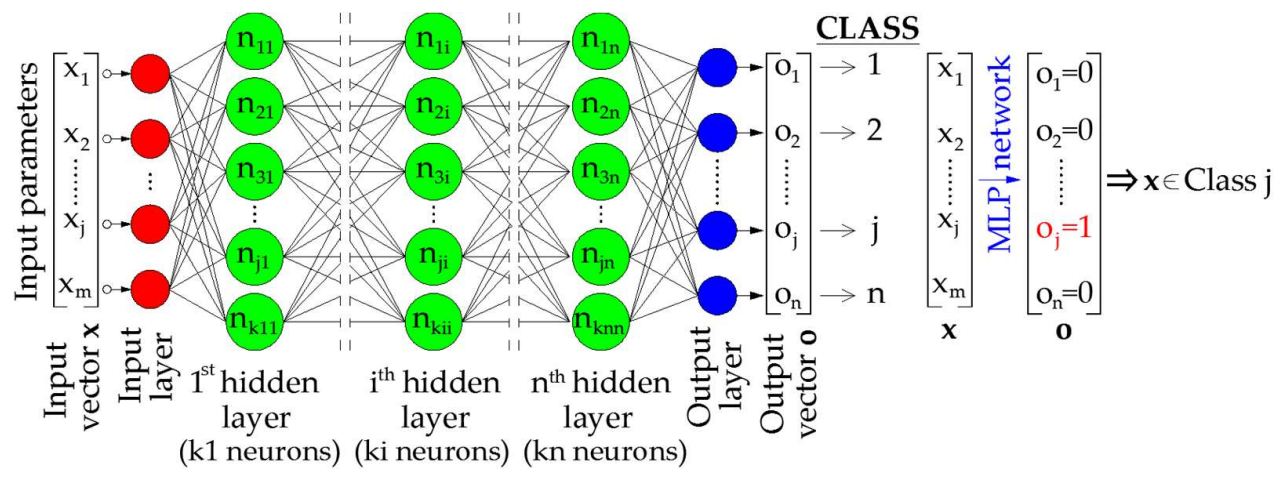

Figure 2. General form of an MLP network configured for the solution of classification problems

As it can be seen from Figure 2 one basic characteristic of the MLP network which is configured for the solution of a classification problem is the number of elements of the output vector $\mathbf{o}$. This number is equal to the number of the pre-defined classes in which the samples $\mathbf{x}$ can be classified. Thus, for a classification problem with $\mathbf{n}$ classes the output vector must have dimension $\mathbf{n} \times 1$. Another one basic characteristic of the modeling of the classification problem by means of MPL networks is the mapping of classes to the values of the elements of the output vector o. More specifically, when the network extracts an output vector $\mathbf{o}$ with $\mathrm{O}_{\mathrm{j}}=1$ and all other elements equal to 0 , then the corresponding sample is classified to class $\mathrm{j}$. As regards the other parameters which are required for the configuration of the MLP networks (i.e. the number of the hidden layers, the number of neurons in each hidden layer and the activation functions), as well as the training algorithms, details are given in section 3 .

\section{Description and formulation of the problem in terms compatible to MLP Networks}

\subsection{General description of the problem and the benefits of the solution using MLP Networks}

The motivation for the current research is based on the idea to deploy the inherent attributes of MLP networks to extract in real time results for multiparameter problems. Thus, in the present paper the ability of MLP networks to predict reliably the level of influence of the seismic incident angle on the SDL of new RC buildings (at the stage of design) or of existing RC buildings (in the framework of the seismic vulnerability assessment procedure) is investigated. In other words, the main target of the current investigation is the proposal of a procedure based on MLP networks which aims to detect in real time the cases for which the critical angle of the seismic excitation significantly alters the expected SDL of RC buildings compared to the SDL which arises when the buildings are analyzed considering that the angle of seismic excitation is equal to zero (i.e. when the two horizontal components of the seismic excitation are considered to be parallel to the structural axes of buildings, see Figure 1). The expected benefit of the proposed procedure is the avoidance of the numerous time-consuming NTHA which are required for the estimation of the critical seismic angle, in those cases where this angle does not lead in fact to significant increase of the SDL. Thus, it becomes feasible to rapidly identify the RC buildings the SDL of which is not sensitive to the angle of seismic excitation. This rapid detection can accelerate the procedure followed for the configuration of new RC build- 
ings at the stage of design, or the procedure for the configuration of existing RC buildings' retrofitting schemes in the framework of seismic vulnerability assessment.

\subsection{Formulation of the problem in terms compatible to MLP Networks}

In order to quantify the criterion which defines the significance (or the insignificance) of the critical seismic angle's influence on the SDL, first of all a Seismic Damage Index (SDI) [47] must be selected. Then, a magnification factor that reflects the increase of the SDI value when the seismic excitation angle takes its critical value $\theta_{\text {cr }}$ regarding to the SDI value which corresponds to the case in which the seismic excitation angle $\theta$ is equal to zero, must be defined. The general form of this factor (Seismic Damage Index Magnification Factor - SDIMF) is given by means of Equation (1).

$\mathrm{SDIMF}=\frac{\text { Seismic Damage Index for } \theta=\theta_{\mathrm{cr}}}{\text { Seismic Damage Index for } \theta=0}=\frac{\operatorname{SDI}\left(\theta=\theta_{\text {cr }}\right)}{\operatorname{SDI}(\theta=0)}>1.0$

After the above definition, a characteristic value of SDIMF (value SDIMF $F_{c}$ for the separation of the range of its values in two sub-spaces, namely the sub-space of values which correspond to the significant influence of the critical incident angle on SDI and the sub-space of values which correspond to the insignificant influence of the critical incident angle on SDI must be selected. However, the verification of this selection is very difficult. Nevertheless, due to the fact that the SDIMF and SDI are related through the Equation (1) it is equivalent to use a corresponding characteristic value for the latter. Thus, the problem is converted to a comparison of the $\operatorname{SDI}\left(\theta=\theta_{\mathrm{cr}}\right)$ value with the characteristic value of SDI (value SDI $)$ which corresponds to the SDIMF. The selection of a value for the SDI can be verified more rationally on the basis of experimental or numerical results which are available in the literature. More specifically, as regards the MIDR index which is used as SDI in the current research, the limit values that defines different SDC for RC buildings are presented in [48]. These values are summarized in Table 1.

Table 1. Definition of 3 or 5 SDC according to MIDR seismic damage index

\begin{tabular}{cccccc}
\hline MIDR [\%] & $<\mathbf{0 . 2 5}$ & $\mathbf{0 . 2 5 - 0 . 5}$ & $\mathbf{0 . 5 - 1 . 0}$ & $\mathbf{1 . 0 - 1 . 5}$ & $>\mathbf{1 . 5}$ \\
\hline SDC (5 classes) & Null & Slight & Moderate & Heavy & Destruction \\
\hline SDC (3 classes) & Slight ("S") & Moderate ("M") & Heavy ("H") \\
\hline Description & $\begin{array}{c}\text { No damages or } \\
\text { repairable damages } \\
\text { in structural system }\end{array}$ & $\begin{array}{c}\text { Significant but } \\
\text { repairable damages } \\
\text { in structural system }\end{array}$ & $\begin{array}{c}\text { Non-repairable } \\
\text { damages in } \\
\text { structural system }\end{array}$ \\
\hline
\end{tabular}

Using the values which are presented in Table 1 the definition of characteristic values for the MIDR is feasible. For example, if three SDC are considered, as is the case in the present paper, then two characteristic values for the MIDR can be defined, namely the value $0.5 \%$ which corresponds to the limit between the Slight ("S") SDC and Moderate ("M") SDC and the value $1.0 \%$ which corresponds to the limit between the "M" SDC and Heavy ("H") SDC. Thus, two different approaches for the formulation of the problem as PR problem were considered in the current study:

- First Approach (Approach 1 or A1). Definition of two classes: the class of buildings for which the $\operatorname{SDC}$ for $\theta=0, \operatorname{SDC}(\theta=0)$, is changed for $\theta=\theta_{\text {cr }}$ (i.e. if $\operatorname{MIDR}<0.5 \%$ for $\theta=0$ becomes MIDR $>0.5 \%$ for $\theta=\theta_{\text {cr }}$ or if $0.5 \%<$ MIDR $<1.0 \%$ for $\theta=0$ becomes MIDR $>1.0 \%$ for $\left.\theta=\theta_{\text {cr }}\right)$, and the class of buildings for which the SDC for $\theta=0, \operatorname{SDC}(\theta=0)$, is not changed for $\theta=\theta_{\text {cr }}$ (i.e. if $\operatorname{MIDR}<0.5 \%$ for $\theta=0$ remains $\operatorname{MIDR}<0.5 \%$ for $\theta=\theta_{\text {cr }}$ or if $0.5 \%<\operatorname{MIDR}<1.0 \%$ for $\theta=0$ remains $0.5 \%<\operatorname{MIDR}<1.0 \%$ for $\theta=\theta_{\mathrm{cr}}$ ). It must be noted that the case in which $\operatorname{MIDR}(\theta=0)>1.0 \%$ is not considered herein because if a building

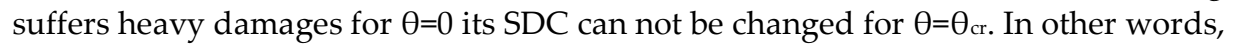
the A1 corresponds to a two class PR problem the solution of which leads to the 
answer to the question if the SDC of an RC building for $\theta=0(\operatorname{SDC}(\theta=0))$ is increased for $\theta=\theta_{\text {cr }}$ (i.e. $\operatorname{SDC}\left(\theta=\theta_{\mathrm{cr}}\right)>\operatorname{SDC}(\theta=0) \rightarrow$ significant influence of $\theta_{\mathrm{cr}}$ ) or not (i.e. $\operatorname{SDC}\left(\theta=\theta_{\mathrm{cr}}\right)=\operatorname{SDC}(\theta=0) \rightarrow$ insignificant influence of $\left.\theta_{\mathrm{cr}}\right)$, regardless of the SDC for $\theta=0$ $(\operatorname{MIDR}(\theta=0)<0.5 \%$ or $0.5 \%<\operatorname{MIDR}(\theta=0)<1.0 \%)$. This approach does not give additional information about the magnitude of change of SDC for $\theta=\theta_{c r}$, but simply gives the information about the change (or not) of SDC.

- Second Approach (Approach 2 or A2). In the framework of the second approach more details about the influence of $\theta_{\text {cr }}$ on the SDC can be extracted. To this end, the buildings are separated in two categories: the buildings which are classified to " $\mathrm{S}$ " SDC for $\theta=0$ (i.e. $\operatorname{MIDR}(\theta=0)<0.5 \%$ ) and to those which are classified to " $\mathrm{M}$ " SDC for $\theta=0$ (i.e. $0.5 \%<\operatorname{MIDR}(\theta=0)<1.0 \%$ ). For buildings which are classified to "S" SDC for $\theta=0$ the problem can be defined as a two or a three class PR problem. More specifically, the consideration of a three class PR problem (Approach 2 / Category 3S, or A2/C3S) leads to the prediction of the exact category of buildings' SDC for $\theta=\theta_{\text {cr }}$ and not only to the prediction about the change (or not) of the SDC for $\theta=\theta_{\text {cr. }}$ In other words, in this case the three classes are defined by means of the following criteria: Class $1 \quad\left\{\operatorname{SDC}(\theta=0)={ }^{\prime \prime} S^{\prime \prime} \rightarrow \operatorname{SDC}\left(\theta=\theta_{\mathrm{cr}}\right)={ }^{\prime \prime} \mathrm{S}^{\prime \prime}\right\}$, Class $2 \quad\left\{\operatorname{SDC}(\theta=0)={ }^{\prime \prime} \mathrm{S}^{\prime \prime} \rightarrow\right.$ $\left.\operatorname{SDC}\left(\theta=\theta_{\text {cr }}\right)={ }^{\prime \prime} \mathrm{M}^{\prime \prime}\right\}$ and Class $3\left\{\operatorname{SDC}(\theta=0)={ }^{\prime \prime} \mathrm{S}^{\prime \prime} \rightarrow \operatorname{SDC}\left(\theta=\theta_{\mathrm{cr}}\right)={ }^{\prime \prime} \mathrm{H}^{\prime \prime}\right\}$. The Class 1 corresponds to insignificant influence of the $\theta_{\mathrm{cr}}$ on the SDC, whereas, on the contrary, the Classes 2 and 3 correspond to significant influence. Correspondingly, in case of the two class PR problem (Approach 2 / Category 2S, or A2/C2S) the two classes are defined by means of the following criteria: Class 1 SSDC $(\theta=0)={ }^{\prime \prime} S^{\prime \prime} \rightarrow$ $\left.\operatorname{SDC}\left(\theta=\theta_{\mathrm{cr}}\right)={ }^{\prime \prime} \mathrm{S}^{\prime \prime}\right\}$ and Class $2\left\{\operatorname{SDC}(\theta=0)={ }^{\prime \prime} \mathrm{S}^{\prime \prime} \rightarrow \operatorname{SDC}\left(\theta=\theta_{\mathrm{cr}}\right)={ }^{\prime \prime} \mathrm{M}^{\prime \prime}\right.$ or $\operatorname{SDC}\left(\theta=\theta_{\mathrm{cr}}\right)=$ " $\left.\mathrm{H}^{\prime \prime}\right\}$. Finally, in the framework of the second approach a separate procedure for buildings which are classified in " $\mathrm{M}$ " SDC for $\theta=0$ is followed (Approach 2 / Category $2 \mathrm{M}$, or $\mathrm{A} 2 / \mathrm{C} 2 \mathrm{M})$. More specifically, in this case only two classes can be defined, i.e. the Class $1\left\{\operatorname{SDC}(\theta=0)={ }^{\prime \prime} \mathrm{M}^{\prime \prime} \rightarrow \operatorname{SDC}\left(\theta=\theta_{\mathrm{cr}}\right)={ }^{\prime \prime} \mathrm{M}^{\prime \prime}\right\}$ and the Class $2\left\{\operatorname{SDC}(\theta=0)={ }^{\prime \prime} \mathrm{M}^{\prime \prime}\right.$ $\rightarrow \operatorname{SDC}\left(\theta=\theta_{\text {cr }}\right)=$ "H" $\mathrm{H}^{\prime}$

The aforementioned two approaches for the solution of the problem of the current study are summarized in Table 2 (in this Table the correspondence of each class to the significance or the insignificance of the influence of $\theta_{\mathrm{cr}}$ on the SDC is also presented).

Table 2. Main characteristics of the Approaches used for the definition of the studied problem

\begin{tabular}{|c|c|c|}
\hline $\begin{array}{l}\text { Approach/ } \\
\text { Category }\end{array}$ & Classes & Criteria of classes / Significant influence of $\theta_{c r}$ \\
\hline \multirow{2}{*}{ A1 } & \multirow{2}{*}{2} & Class 1: $\operatorname{SDC}\left(\theta=\theta_{\mathrm{cr}}\right)=\operatorname{SDC}(\theta=0) / \mathrm{NO}$ \\
\hline & & Class 2: $\operatorname{SDC}\left(\theta=\theta_{\mathrm{cr}}\right)>\operatorname{SDC}(\theta=0) / \mathrm{YES}$ \\
\hline \multirow{3}{*}{$\mathrm{A} 2 / \mathrm{C} 3 \mathrm{~S}$} & \multirow{3}{*}{3} & Class 1: $\operatorname{SDC}(\theta=0)=" S^{\prime \prime} \rightarrow \operatorname{SDC}\left(\theta=\theta_{\mathrm{cr}}\right)=" \mathrm{~S}^{\prime \prime} / \mathrm{NO}$ \\
\hline & & Class 2: $\operatorname{SDC}(\theta=0)=" \mathrm{~S}^{\prime \prime} \rightarrow \operatorname{SDC}\left(\theta=\theta_{\mathrm{cr}}\right)={ }^{\prime \prime} \mathrm{M}^{\prime \prime} / \mathrm{YES}$ \\
\hline & & Class 3: $\operatorname{SDC}(\theta=0)=" S^{\prime \prime} \rightarrow \operatorname{SDC}\left(\theta=\theta_{\mathrm{cr}}\right)=" \mathrm{H}^{\prime \prime} / \mathrm{YES}$ \\
\hline \multirow{2}{*}{$\mathrm{A} 2 / \mathrm{C} 2 \mathrm{~S}$} & \multirow{2}{*}{2} & Class 1: $\operatorname{SDC}(\theta=0)={ }^{\prime \prime} S^{\prime \prime} \rightarrow \operatorname{SDC}\left(\theta=\theta_{\mathrm{cr}}\right)=" \mathrm{~S}^{\prime \prime} / \mathrm{NO}$ \\
\hline & & Class 2: $\operatorname{SDC}(\theta=0)=" S " \rightarrow \operatorname{SDC}\left(\theta=\theta_{\mathrm{cr}}\right)=" \mathrm{M}$ " or "H" / YES \\
\hline \multirow{2}{*}{$\mathrm{A} 2 / \mathrm{C} 2 \mathrm{M}$} & \multirow{2}{*}{2} & Class 1: $\operatorname{SDC}(\theta=0)={ }^{\prime \prime} \mathrm{M}^{\prime \prime} \rightarrow \operatorname{SDC}\left(\theta=\theta_{\mathrm{cr}}\right)={ }^{\prime \prime} \mathrm{M}^{\prime \prime} / \mathrm{NO}$ \\
\hline & & Class 2: $\operatorname{SDC}(\theta=0)={ }^{\prime \prime} \mathrm{M}^{\prime \prime} \rightarrow \operatorname{SDC}\left(\theta=\theta_{\mathrm{cr}}\right)=$ "H" $/ \mathrm{YES}$ \\
\hline
\end{tabular}

Obviously, the A1 concerns all buildings regardless of their classification to an SDC for $\theta=0$. Thus, this approach is applicable whether the classification of buildings to SDC for $\theta=0$ is known or not. On the contrary, if the A2 is chosen the problem is solved selecting one of the categories $\mathrm{A} 2 / \mathrm{C} 3 \mathrm{~S}$ or $\mathrm{A} 2 / \mathrm{C} 2 \mathrm{~S}$ in combination to the category $\mathrm{A} 2 / \mathrm{C} 2 \mathrm{M}$. In other words, the solution of the problem using the A2 is achieved by the selection to 
formulate it using one of the following pairs (Analysis Types): "A2/(C3S + C2M)" or "A2/(C2S + C2M)". Thus, the solution of the problem using one of the two types of A2 is feasible only if the SDC of buildings for $\theta=0$ is known.

The categories of the MLP networks which were used for each one of the aforementioned alternative formulations of the problem are summarized in Table 3 . It must be noted that the names of networks in Table 3 concern the type of Analysis. The complete names of them also contain the version of buildings (BB, RIB, IIB) as it will be presented in section 4 .

Table 3. Main characteristics of the types of analyses and the corresponding names of networks

\begin{tabular}{|c|c|c|}
\hline Analysis Type & Names of Networks & Number of Classes \\
\hline “A1" & NA1 (all buildings) & 2 \\
\hline \multirow{2}{*}{ “A2/(C3S+C2M)” } & NA2C3S (buildings classified to SDC “S” for $\theta=0$ ) & 3 if $\operatorname{SDC}(\theta=0)=" S^{\prime \prime}$ \\
\hline & NA2C2M (buildings classified to SDC “M" for $\theta=0$ ) & 2 if $\operatorname{SDC}(\theta=0)=" \mathrm{M}^{\prime \prime}$ \\
\hline \multirow{2}{*}{ "A2/(C2S+C2M)" } & NA2C2S (buildings classified to SDC “S” for $\theta=0$ ) & 2 if $\operatorname{SDC}(\theta=0)=" S^{\prime \prime}$ \\
\hline & NA2C2M (buildings classified to SDC “M" for $\theta=0$ ) & 2 if $\operatorname{SDC}(\theta=0)=" \mathrm{M}^{\prime \prime}$ \\
\hline
\end{tabular}

On the basis of the selected approach (A1 or A2) the general form of the procedure for the investigation of the significance (or the insignificance) of the influence of the critical seismic angle on RC buildings' SDC (considering that the used MLP networks are already trained), which is used in the current study, is described by means of the flowcharts of Figure 3.

It must be noted that when the A2 approach is used there are two alternatives for the estimation of the $\operatorname{SDC}(\theta=0)$ : (a) with application of NTHA or (b) using MLP networks (Figure 3(b)). In order to adopt the alternative (b) it is necessary appropriately trained networks to be available (NӨ0 networks in Figure 3(b)). These networks must be trained in parallel with the networks which predict the level of influence of $\theta_{\text {cr }}$ on SDC. The procedure and the details for the configuration and the training of NO0 networks are given by Morfidis and Kostinakis [32]. However, in the present study the source of the information about the classification of buildings in SDC for $\theta=0$ (i.e. NTHA or N $\theta 0$ networks) does not affect the procedure of investigation. 


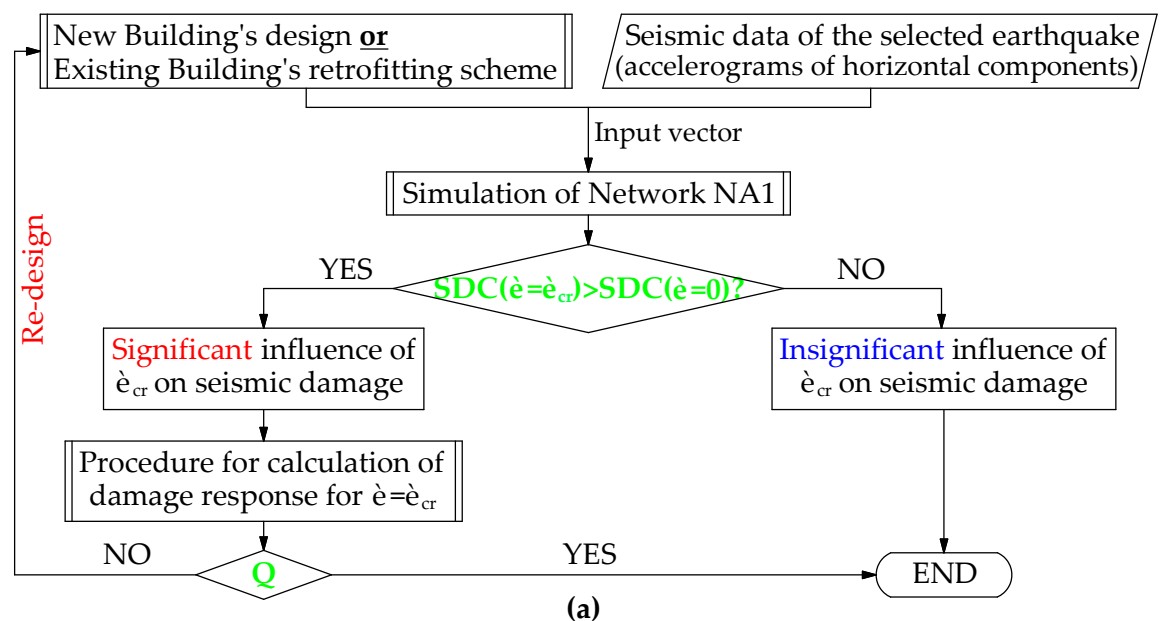

(a)

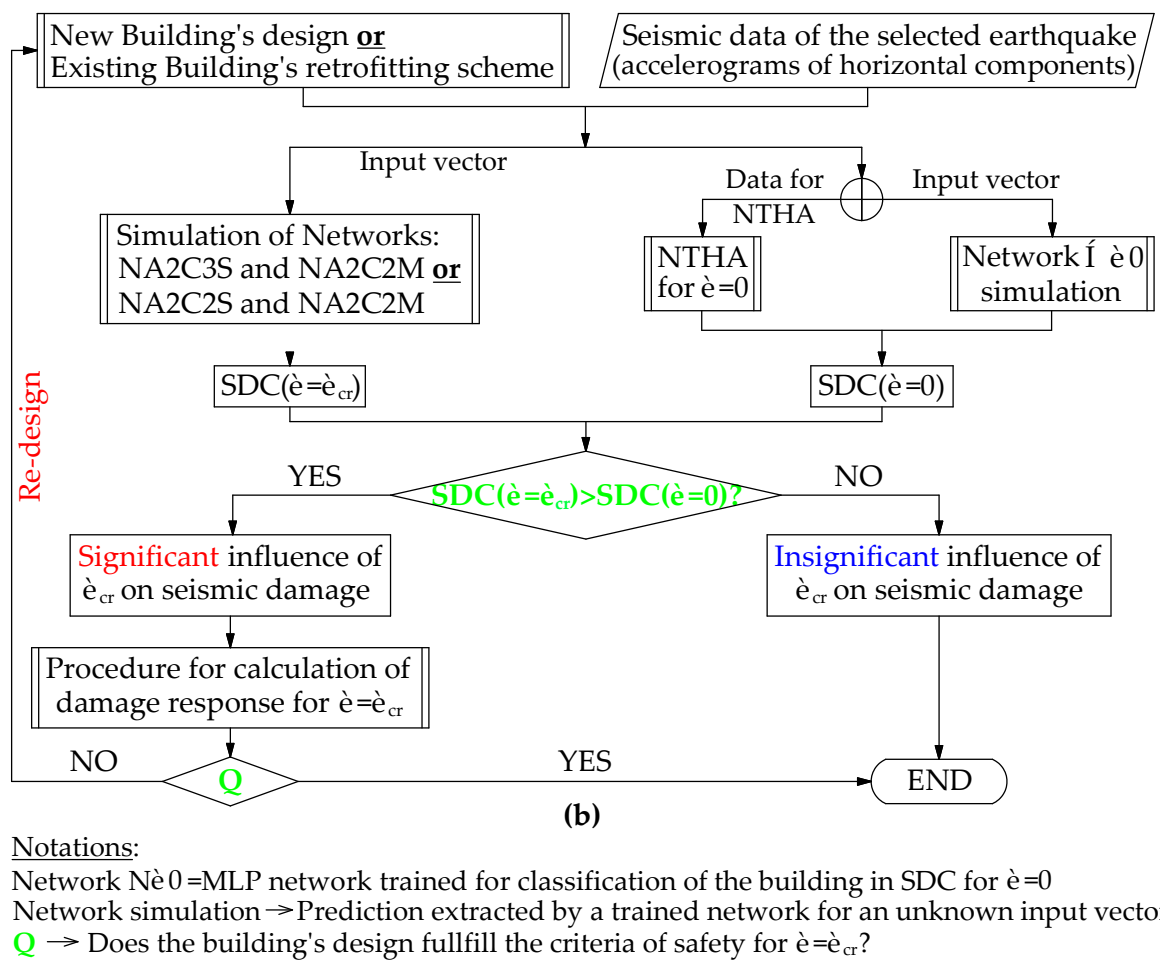

Figure 3. General flowcharts of the procedure for the study of the critical seismic angle's influence on the SDC of RC buildings: (a) Approach A1, (b) Approach A2

\subsection{Selection of ground motions, $R C$ buildings and the training data set generation}

The training data-set generation using numerical procedures requires initially properly selection of RC buildings and ground motion records. After these selections, as it is well-known, the training data-set is generated through a series of NTHA of each one of the selected buildings for all the selected ground motion records. The whole procedure for the generation of a training data-set using numerical approach is fully described in [32]. This type of procedure was also used in the present study. However, a significant differentiation was necessary herein. More specifically, on the contrary to the procedure which is described in [32], each one of the selected RC building was analyzed for all the selected ground motion records not only considering seismic angle $\theta=0$, but considering seismic angles between 0 and 355 degrees $\left(\theta=0^{\circ}, 5^{\circ}, 10^{\circ}, \ldots ., 355^{\circ}\right)$, as it is illustrated in Figure 4 (for more details see also [6]). Therefore, for each one of the selected RC build- 
ings and each one of the selected ground motion records 72(=360/5) NTHA were performed. The seismic angle for which the MIDR value is maximized is the $\theta_{\text {cr. }}$ Then, based to the corresponding MIDR values, the classification of each one of the selected RC buildings in the three pre-defined SDC of Table 1 for the seismic angles $\theta=0(\operatorname{SDC}(\theta=0))$ and $\theta=\theta_{\text {cr }}\left(\operatorname{SDC}\left(\theta=\theta_{\text {cr }}\right)\right)$ is accomplished and stored using the procedure of Figure $4(\mathrm{~b})$. Finally, the sets of target vectors in forms compatible to the approaches A1 and A2 (Table 2 and Table 3) are formed.

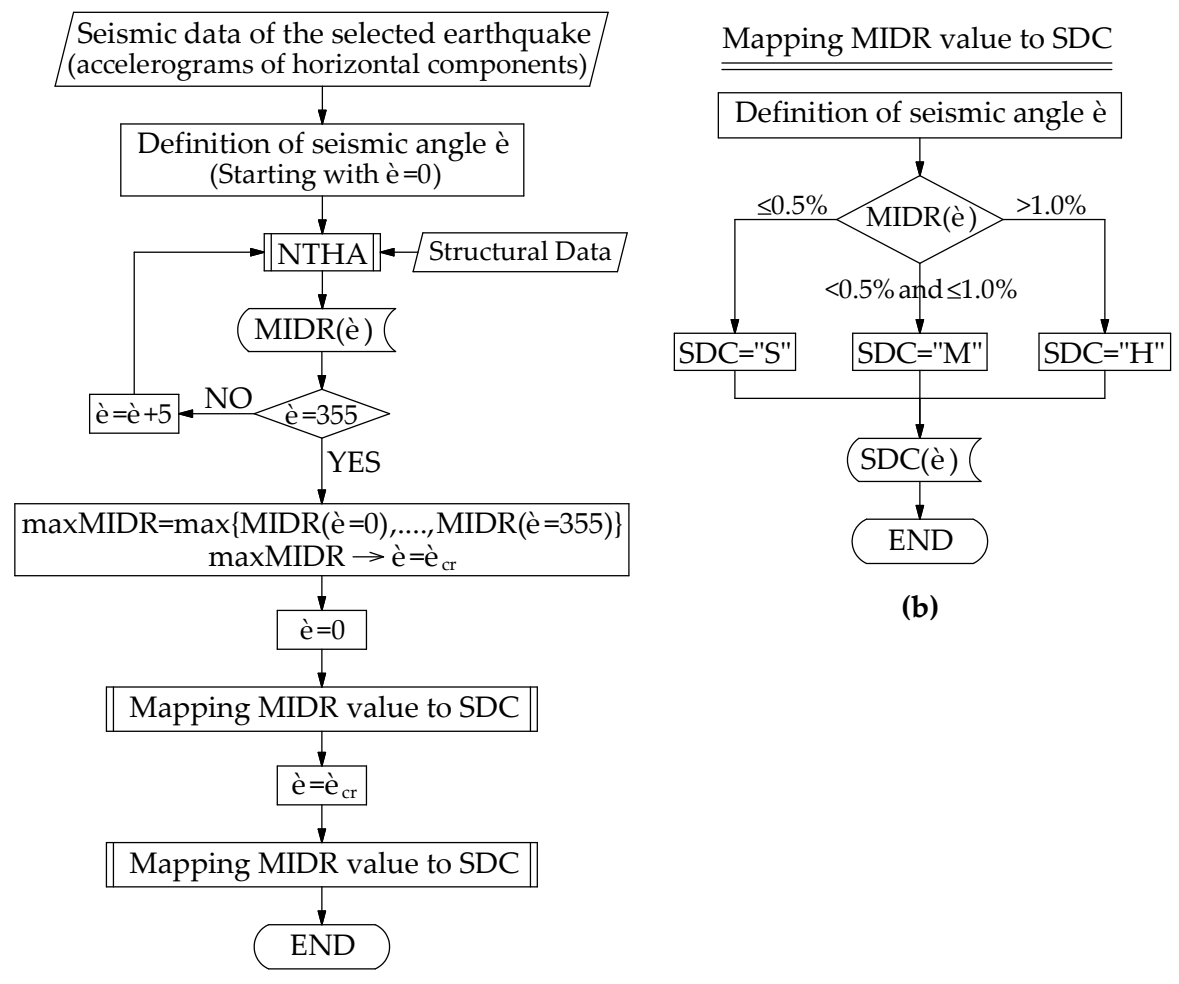

(a)

Figure 4. Flowchart of the procedure used for the generation of the training data-sets

As regards the selected RC buildings, 30 different types regarding their structural system were configured, modelled and designed according to the provisions of EN1992-1-1 [49] and EN1998-1 [16]. These buildings are regular in elevation according to EN1998-1. Due to the fact that the selected buildings were used in previous published research works of authors, more details and fully description about their configuration and modelling (for the design purposes and the NTHA) can be found in [32,33]. However, it must be stressed herein that for each one of the 30 selected RC buildings three different versions were considered as regards their masonry infills (see also [33]): (i) Buildings without masonry infills (ㅁare Buildings or BB), (ii) Buildings with masonry infills in all storeys (ㄹegularly $\underline{\text { Infilled }}$ Buildings or RIB) and (iii) Buildings with masonry infills in all storeys except of the ground storey (Irregularly Infilled Buildings or IIB). For each one of these three versions of buildings, separate training data-sets were generated according to approaches A1 and A2 (Table 2 and Table 3). Thus, all analyses which are presented in the current paper (section 4) were performed separately for each one of the three aforementioned versions of the selected buildings.

Finally, as regards the selected seismic ground motions, the 65 ground motion records which are presented in [32] were also used in the current study. Therefore, for the generation of each one of the three training data-sets $140400(=30$ buildings $x 65$ ground motions $\times 72$ seismic angles) NTHA were performed. This means that the procedure 
which is described in Figure 4 was performed 140400/72=1950 times for each one of the three versions of the 30 selected RC buildings. The number of the target vectors and their form (which corresponds to the networks that are presented in Table 3) for each one of the three versions of the selected RC buildings are given in Table 4.

Table 4. Number of samples and the form of target vectors for each one of the networks and the versions of the selected RC buildings

\begin{tabular}{|c|c|c|}
\hline Network & Number of samples & Form of Target Vectors (TV) \\
\hline \multirow{2}{*}{ NA1 } & BB: 1006(=1950-944*), RIB: & $\mathrm{TV}=\left[\begin{array}{ll}1 & 0\end{array}\right]^{\mathrm{T}}$ (Class 1$)$ \\
\hline & $1539\left(=1950-411^{*}\right)$, IIB: $1052\left(=1950-898^{*}\right)$ & $\mathrm{TV}=\left[\begin{array}{ll}0 & 1\end{array}\right]^{\mathrm{T}}($ Class 2) \\
\hline \multirow{3}{*}{ NA2C3S } & BB: 563(=1950-443-944*), & $\mathrm{TV}=\left[\begin{array}{lll}1 & 0 & 0\end{array}\right]^{\mathrm{T}}($ Class 1$)$ \\
\hline & RIB: $1075\left(=1950-464-411^{*}\right)$, & $\mathrm{TV}=\left[\begin{array}{lll}0 & 1 & 0\end{array}\right]^{\mathrm{T}}$ (Class 2) \\
\hline & IIB: $673\left(=1950-379-898^{*}\right)$ & $\mathrm{TV}=\left[\begin{array}{lll}0 & 0 & 1\end{array}\right]^{\mathrm{T}}($ Class 3$)$ \\
\hline \multirow{2}{*}{$\mathrm{NA} 2 \mathrm{C} 2 \mathrm{~S}$} & \multirow{2}{*}{ BB: 563, RIB: 1075, IIB: 673} & $\mathrm{TV}=\left[\begin{array}{ll}1 & 0\end{array}\right]^{\mathrm{T}}($ Class 1$)$ \\
\hline & & $\mathrm{TV}=\left[\begin{array}{ll}0 & 1\end{array}\right]^{\mathrm{T}}$ (Class 2) \\
\hline \multirow[b]{2}{*}{$\mathrm{NA} 2 \mathrm{C} 2 \mathrm{M}$} & BB: 443(=1950-563-944*), RIB: & $\mathrm{TV}=\left[\begin{array}{ll}1 & 0\end{array}\right]^{\mathrm{T}}($ Class 1$)$ \\
\hline & $\begin{array}{c}464\left(=1950-1075-411^{*}\right), \mathrm{IIB}: \\
379\left(=1950-673-898^{*}\right)\end{array}$ & $\mathrm{TV}=\left[\begin{array}{ll}0 & 1\end{array}\right]^{\mathrm{T}}$ (Class 2) \\
\hline
\end{tabular}

*Number of samples which are classified in SDC “ $\mathrm{H}$ " for $\theta=0$

\subsection{Selection of parameters for the input vectors}

A very important part of the current study was the selection of parameters for the input vectors of the used MLP networks. Generally, in problems which concern the prediction of the seismic damage of buildings the input vectors of the MLP networks must contain seismic and structural parameters (see e.g. $[23,28,29,50,51]$ ).

As regards the seismic parameters, previous research works indicate that the well-documented seismic parameters which are defined and used in the specific literature (see e.g. [52]) led to reliable results. Taking into consideration that in analyses of 3D RC buildings the vertical component of earthquake records is usually neglected (except for the case of structures with special characteristics which are not the subject of the current study) the input vectors must contain values of seismic parameters which are extracted from a selected combination rule of their values along the two horizontal components of the excitation (i.e. their geometric mean value, e.g. [53]). However, due to the fact that the target of the current study is the investigation of the influence of $\theta_{\text {cr }}$ on the SDL of RC buildings it is more rational to select as seismic parameters in the input vectors the ratios of their values along the two horizontal components of the seismic excitation rather than their values extracted by a combination rule. Thus, the ratios of the minimum to the maximum value of the selected seismic parameters were used in input vectors for MLP networks, as it is presented by the general Equation (2).

$\mathrm{SIP}=\frac{\min \{\operatorname{SIP}(\operatorname{dir} 1) ; \operatorname{SIP}(\operatorname{dir} 2)\}}{\max \{\operatorname{SIP}(\operatorname{dir} 1) ; \operatorname{SIP}(\operatorname{dir} 2)\}}$

Where:

SIP is the value of the Seismic Input Parameter which is introduced to the input vector, $\mathrm{SIP}(\operatorname{dir} 1)$ is the value of the Seismic Input Parameter which is extracted from the accelerogram that corresponds to the horizontal direction 1 of the seismic excitation, SIP(dir2) is the value of the Seismic Input Parameter which is extracted from the accelerogram that corresponds to the horizontal direction 2 of the seismic excitation.

It must be noted that the directions 1 and 2 correspond to the horizontal axes along which the seismic excitations' accelerograms are recorded (see Figure 1). 
The selection of seismic parameters was based on the corresponding selection which was made in previous published research works of authors (see e.g. [32]) but it was necessary to make some changes herein. More specifically, the seismic parameters which are based on the earthquakes' duration, namely the Uniform Duration, the Bracketed Duration and the Significant Duration (see e.g. [52]) were excluded due to the fact that their values for one or for both of the horizontal directions for some of the 65 earthquakes used for the generation of the training data set are equal to zero. This fact led to problems in the application of Equation (2) (0/0 ratios). Thus, the selected seismic parameters which are introduced in the input vectors in the present study are 12 and are summarized in Table 5.

Table 5. The selected seismic parameters for the input vectors of MLP networks

\begin{tabular}{lccc}
\hline 1 & Peak Ground Acceleration (PGA) & 7 & Acceleration Spectrum Intensity (ASI) \\
2 & Peak Ground Velocity (PGV) & 8 & Cumulative Absolute Velocity (CAV) \\
3 & Specific Energy Density (SED) & 9 & Peak Ground Displacement (PGD) \\
4 & Arias Intensity (Ia) & 10 & Effective Peak Acceleration (EPA) \\
5 & Predominant Period (PP) & 11 & Sustained Max Acceleration (SMA) \\
6 & Housner Intensity (HI) & 12 & Sustained Max Velocity (SMV) \\
\hline
\end{tabular}

Many structural parameters can be used for the description of the seismic response of RC buildings. These parameters generally quantify the stiffness and the strength of buildings under seismic loads. The nature of the present study, which concerns in fact mainly a geometric problem, and the above described rationale of selection of the seismic input parameters (Equation (2)) led to the selection of the following three Structural Input Parameters (StIP):

(a) The ratio of the minimum to the maximum value of uncoupled fundamental natural periods $T_{1, X}, T_{1, Y}$ of buildings for pure vibration along their structural axes $X, Y$ (see Figure 5) respectively.

$$
\text { StIP1 }=\frac{\min \left\{\mathrm{T}_{1, \mathrm{X}} ; \mathrm{T}_{1, \mathrm{Y}}\right\}}{\max \left\{\mathrm{T}_{1, \mathrm{X}} ; \mathrm{T}_{1, \mathrm{Y}}\right\}}
$$

This parameter is an index of the relative horizontal stiffness of buildings along their two orthogonal structural axes.

(b) The ratio of the buildings' total height $\mathrm{H}_{\text {tot }}$ to the square root of the sum of squares of the horizontal dimensions Lx and Ly of their plans along the structural axes X, Y (see Figure 5).

$$
\mathrm{StIP} 2=\frac{\mathrm{H}_{\text {tot }}}{\sqrt{\mathrm{L}_{\mathrm{X}}^{2}+\mathrm{L}_{\mathrm{Y}}^{2}}}
$$

This parameter expresses the slenderness of buildings and plays a significant role to their seismic response because it gives an additional index of the horizontal stiffness. It must be noted that this parameter can be defined not only in case of buildings with rectangular plan but also in any case using equivalent horizontal dimensions along the structural axes X, Y (see Figure 5). 

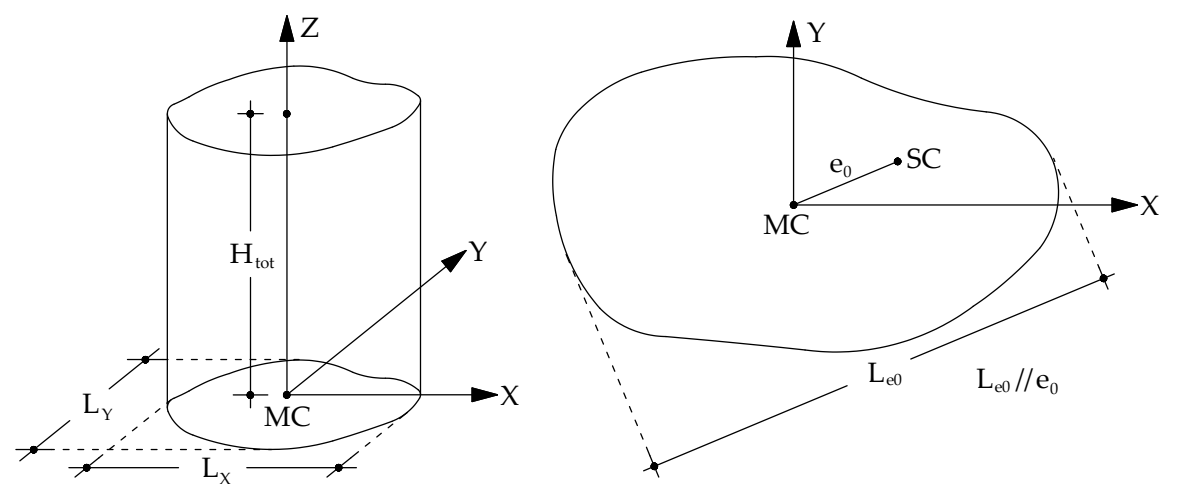

Figure 5. Definition of the selected structural parameters for the input vectors of MLP networks

(c) The ratio of the structural eccentricity (i.e. the distance between the mass center (MC) and the stiffness center (SC) of storeys) eo to the dimension of plan of the building which is parallel to it (see Figure 5).

$$
\mathrm{StIP} 3=\frac{\mathrm{e}_{0}}{\mathrm{~L}_{\mathrm{e} 0}}
$$

This parameter indicates the degree of the eccentricity of the forces induced by seismic excitations. It is well-documented that this degree affects significantly the level of seismic damage.

Therefore, in the current research 15 input parameters (12 seismic parameters and 3 structural parameters) were used as elements of the input vectors of MLP networks. The general form of these input vectors (dimensions 15x1) is given by Equation (6).

$$
\begin{aligned}
& \mathbf{X}=\left[\begin{array}{ll}
\mathbf{x}_{\text {seism }} & \mathbf{x}_{\text {struct }}
\end{array}\right]^{\mathrm{T}}
\end{aligned}
$$

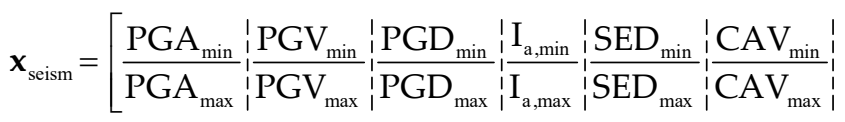

$$
\begin{aligned}
& \left.\frac{\mathrm{ASI}_{\text {min }}}{\mathrm{ASI}_{\text {max }}}\left|\frac{\mathrm{HI}_{\text {min }}}{\mathrm{HI}_{\text {max }}}: \frac{\mathrm{EPA}_{\text {min }}}{\mathrm{EPA}_{\text {max }}}\right| \frac{\mathrm{SMA}_{\text {min }}}{\mathrm{SMA}_{\text {max }}}\left|\frac{\mathrm{PP}_{\text {min }}}{\mathrm{PP}_{\text {max }}}\right| \frac{\mathrm{SMV}_{\text {min }}}{\mathrm{SMV}_{\text {max }}}\right]^{\mathrm{T}} \\
& \mathbf{x}_{\text {struct }}=\left[\begin{array}{l:::c:c}
\min \left\{\mathrm{T}_{1, \mathrm{X}} ; \mathrm{T}_{1, \mathrm{Y}}\right\} & \mathrm{H}_{\mathrm{tot}} & \mathrm{e}_{0} \\
\hdashline \max \left\{\mathrm{T}_{1, \mathrm{X}} ; \mathrm{T}_{1, \mathrm{Y}}\right\} & \sqrt{\mathrm{L}_{\mathrm{X}}^{2}+\mathrm{L}_{\mathrm{Y}}^{2}} & \mathrm{~L}_{\mathrm{e} 0}^{\mathrm{T}}
\end{array}\right]^{\mathrm{T}}
\end{aligned}
$$

\subsection{Parametric investigation for the optimum configuration of the used MLP networks}

It is well-known that the performance of the MLP networks is strongly affected by their configuration, i.e. the selection of the parameters which constitute their structure (Figure 2). These parameters are the number of hidden layers, the neurons in each one of the hidden layers and the activation functions of neurons (see e.g. [54]). Furthermore, additional choices affect the solution of problems by means of MLP networks. These are: the normalization functions of the input and output vectors, the procedure for the partitioning of the generated data-set in training, validation and testing subsets, the performance evaluation parameters and the training algorithms.

In the current study the choices for the aforementioned parameters are summarized in Figure 6. More details about the procedure of the parametric investigation for the optimum selection of the parameters which affect the performance MLP networks are presented in [32]. The results of this investigation are demonstrated and discussed in section 4 . 


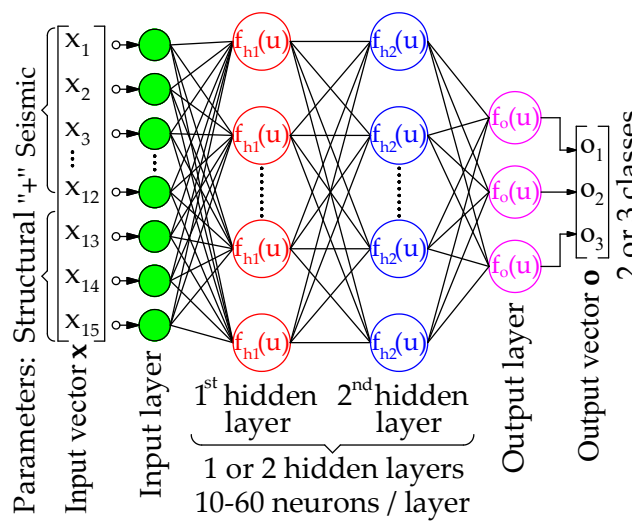

Activation functions: $\mathrm{f}_{\mathrm{h} 1}(\mathrm{u}), \mathrm{f}_{\mathrm{h} 2}(\mathrm{u}), \mathrm{f}_{\mathrm{i}}(\mathrm{u})$

(a) Sigmoid (logsig): $1 /\left(1+\mathrm{e}^{-\mathrm{u}}\right)$

(b) Hyperbolic tangent (tansig): $\left(1-\mathrm{e}^{-\mathrm{u}}\right) /\left(1+\mathrm{e}^{-\mathrm{u}}\right)$

Partition ratios of data sub-sets:

Training / Testing / Validation: 70\%/15\%/15\%

(Randomly composed)

Normalization functions:

Input vector: $-1<x_{i}^{\text {norm }}=2 \cdot \frac{x_{i}-\min x_{i}^{d / s}}{\max x_{i}^{d / s}-\min x_{i}^{d / s}}-1<1$

Output vector: $\mathrm{o}_{\mathrm{j}}=0.5 \cdot\left(\mathrm{o}_{\mathrm{j}}^{\text {norm }}+1\right)$

$\mathrm{d} / \mathrm{s}=$ training data set, $\mathrm{i}=1-15, \mathrm{j}=1-(2$ or 3$)$

Training algorithms:

(a) Resilient Backpropagation (RP)

(b) Scaled Conjugate Gradient (SCG)

Figure 6. The general form of the used networks and the investigated configuration parameters

\section{Presentation and evaluation of the results of the training procedures}

In the current section the results extracted from the procedures which were described in section 3 are presented and evaluated. The basic performance evaluation metric for the studied MLP networks is the Overall Accuracy (OA) index. The OA is the ratio of the samples of a data-set which are classified to the correct class to the total number of samples of this data-set. This index is usually a part of the Confusion Matrices (CM) (see e.g. $[34,55])$. Additionally, other parameters which are defined in CMs are also used if the OA comparisons do not lead to clear conclusions. Thus, the entire CMs are also presented. As it is presented in Figure 6 the generated data-set (sub-section 3.3) it is partitioned (for the purposes of the training procedures) in three sub-sets: the training sub-set, the validation sub-set and the testing sub-set. The results of the investigations for the optimum configuration of the MLP networks using the selected metrics (OA index and the other indices of $\mathrm{CMs}$ ) are presented for the testing sub-set, the training sub-set as well as for the total data-set in any case. However, the performance evaluation using the selected metrics is based on the testing sub-sets because these sub-sets extract reliable estimations about the generalization ability of the MLP networks (i.e. contribute to the check of existence (or non-existence) of overfitting during the training procedure (see e.g. $[56,57]))$.

As it was noted in sub-section 3.2. the two approaches for the solution of the problem (A1, A2) lead to three different analysis types (Table 3). The two different types of approach A2 (i.e. "A2/(C3S+C2M)" and "A2/(C2S+C2M)") differ only in the definition of the number of $\operatorname{SDC}\left(\theta=\theta_{\mathrm{cr}}\right)$ for buildings which are classified in " $\mathrm{S}$ " class for $\theta=0$ (three $\operatorname{SDC}\left(\theta=\theta_{\mathrm{cr}}\right)$ in case of $\mathrm{C} 3 \mathrm{~S}$ and two $\operatorname{SDC}\left(\theta=\theta_{\mathrm{cr}}\right)$ in case of $\left.\mathrm{C} 2 \mathrm{~S}\right)$. On the contrary, the number of classes for buildings which are classified in SDC " $\mathrm{M}$ " for $\theta=0$ is two in any case (Table 3). Therefore, in order to compare the approaches A1 and A2, the comparison of the two types of the approach A2 must be performed initially. More specifically, the categories C3S and C2S must be compared firstly and then the more reliable between them, in conjunction with C2M, can be compared with the approach A1.

The whole procedure for the evaluation of the proposed Approaches A1 and A2 was performed separately for the three different versions of the selected RC buildings (i.e. BB, RIB, IIB). Thus, the presentation of the results follows this rationale. Finally, it must be noted that the presentation of the results in this section is separated in three parts. In the first part (section 4.1.) the results of the investigation for the optimum configured MLP networks for the approach A1 are presented and discussed. The second part (section 4.2.) concerns the corresponding procedure for the Approach A2. Finally, in the third part (section 4.3.) the results of the comparison between the optimum configured MLP networks of the two approaches are discussed. 


\subsection{Optimum configuration of the MLP networks used for the implementation of Approach A1}

In Figure 7 the values of the OA index for the three versions of the selected RC buildings are presented. More specifically, this figure contains the maximum values of OA index which are extracted by the optimum configured MLP networks with one or two hidden layers trained using the Resilient Backpropagation (RP) algorithm (see e.g. [58]) and the Scaled Conjugate Gradient (SCG) algorithm (see e.g. [59]). In Table 6 the corresponding configuration parameters of the optimum MLP networks (number of hidden layers, number of neurons/hidden layer and activation functions of neurons) which extract the OA values of Figure 7 are summarized.
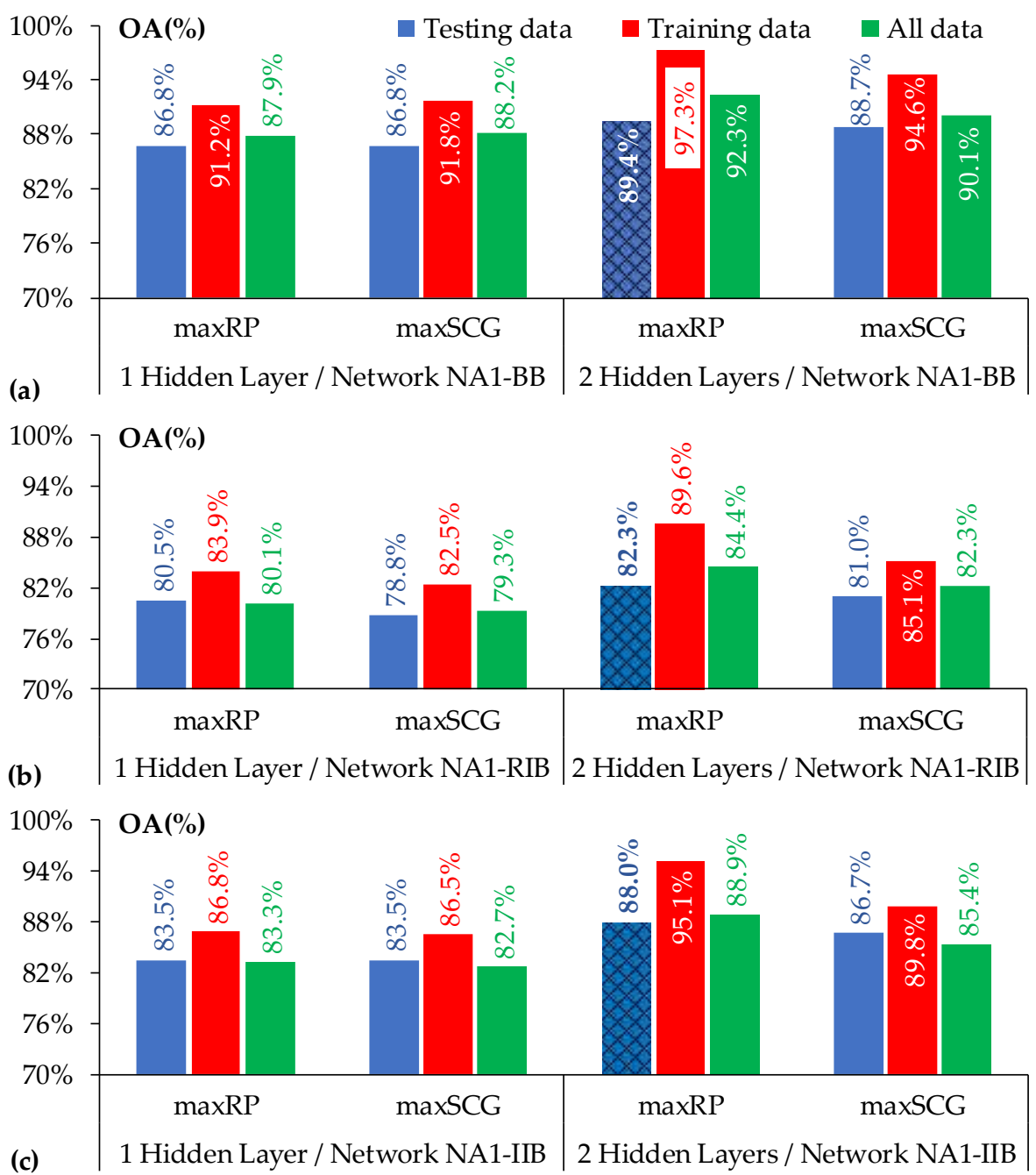

Figure 7. Maximum OA index values extracted by NA1 networks with 1 or 2 hidden layers: (a) BB, (b) RIB, (c) IIB

From the study of Figure 7 the following main conclusions can be mentioned:

- The networks with two hidden layers extract greater OA values than the networks with one hidden layer. However, the differences between them are not significant. More specifically, in case of training using the RP algorithm these differences fluctuate between $3.1 \%-6.7 \%$ for BB, $2.2 \%-6.7 \%$ for RIB and $5.3 \%-9.5 \%$ for IIB. The corresponding fluctuations in case of training using SCG algorithm are $2.1 \%-3.1 \%(\mathrm{BB})$, $2.7 \%-3.8 \%$ (RIB) and $3.2 \%-3.8 \%$ (IIB).

- As regards the evaluation of the used training algorithms for the networks with two hidden layers, the RP algorithm is in any case more effective than the SCG algo- 
rithm. However, the extracted OA index values are in general acceptable regardless the used training algorithm. More specifically, the RP algorithm extracts OA values higher than $82 \%$ (in case of $\mathrm{BB}$ and IIB are almost equal to $90 \%$ ), whereas, the corresponding values extracted by the SCG algorithm are slightly smaller.

The basic conclusion which can be extracted from the study of Table 6 is that, with only one exception, the configuration of all optimum networks includes the Tansig activation function in the output layer.

Table 6. The parameters of the optimum configured networks used for the implementation of A1

\begin{tabular}{|c|c|c|c|c|c|c|c|c|c|c|c|c|c|}
\hline \multirow{3}{*}{\multicolumn{2}{|c|}{$\begin{array}{r}\text { Version of buildings } \\
\text { Training Algorithm } \\
\text { Number of HL }\end{array}$}} & \multicolumn{4}{|c|}{ BB } & \multicolumn{4}{|c|}{ RIB } & \multicolumn{4}{|c|}{ IIB } \\
\hline & & \multicolumn{2}{|c|}{$\mathbf{R P}$} & \multicolumn{2}{|c|}{ SCG } & \multicolumn{2}{|c|}{$\mathbf{R P}$} & \multicolumn{2}{|c|}{ SCG } & \multicolumn{2}{|c|}{$\mathbf{R P}$} & \multicolumn{2}{|c|}{ SCG } \\
\hline & & 1 & 2 & 1 & 2 & 1 & 2 & 1 & 2 & 1 & 2 & 1 & 2 \\
\hline \multirow{2}{*}{$\begin{array}{l}\text { Training } \\
\text { data set }\end{array}$} & $\begin{array}{l}\text { Activation } \\
\text { Functions }\end{array}$ & $\mathrm{T} / \mathrm{T}$ & $\mathrm{T} / \mathrm{T} / \mathrm{T}$ & $\mathrm{T} / \mathrm{T}$ & $\mathrm{T} / \mathrm{L} / \mathrm{T}$ & $\mathrm{T} / \mathrm{T}$ & $\mathrm{T} / \mathrm{T} / \mathrm{T}$ & $\mathrm{L} / \mathrm{T}$ & $\mathrm{T} / \mathrm{T} / \mathrm{T}$ & $\mathrm{T} / \mathrm{T}$ & $\mathrm{T} / \mathrm{T} / \mathrm{T}$ & $\mathrm{T} / \mathrm{T}$ & $\mathrm{T} / \mathrm{T} / \mathrm{T}$ \\
\hline & Neurons/HL & 60 & $60 / 50$ & 52 & $48 / 52$ & 46 & $52 / 52$ & 30 & $52 / 48$ & 56 & $50 / 46$ & 46 & $58 / 46$ \\
\hline \multirow{2}{*}{$\begin{array}{l}\text { Testing } \\
\text { data set }\end{array}$} & $\begin{array}{l}\text { Activation } \\
\text { Functions }\end{array}$ & $\mathrm{T} / \mathrm{T}$ & $\mathrm{L} / \mathrm{L} / \mathrm{T}$ & $\mathrm{L} / \mathrm{T}$ & $\mathrm{T} / \mathrm{T} / \mathrm{T}$ & $\mathrm{T} / \mathrm{T}$ & $\mathrm{L} / \mathrm{L} / \mathrm{T}$ & $\mathrm{L} / \mathrm{T}$ & $\mathrm{T} / \mathrm{L} / \mathrm{T}$ & $\mathrm{L} / \mathrm{T}$ & $\mathrm{T} / \mathrm{T} / \mathrm{T}$ & $\mathrm{T} / \mathrm{T}$ & $\mathrm{L} / \mathrm{T} / \mathrm{L}$ \\
\hline & Neurons/HL & 30 & $36 / 34$ & 14 & $28 / 50$ & 30 & $28 / 14$ & 52 & $58 / 52$ & 24 & $20 / 10$ & 14 & $10 / 12$ \\
\hline \multirow{2}{*}{$\begin{array}{c}\text { Total } \\
\text { data set }\end{array}$} & $\begin{array}{l}\text { Activation } \\
\text { Functions }\end{array}$ & $\mathrm{L} / \mathrm{T}$ & $\mathrm{T} / \mathrm{T} / \mathrm{T}$ & $\mathrm{T} / \mathrm{T}$ & $\mathrm{T} / \mathrm{L} / \mathrm{T}$ & $\mathrm{T} / \mathrm{T}$ & $\mathrm{T} / \mathrm{T} / \mathrm{T}$ & $\mathrm{T} / \mathrm{T}$ & $\mathrm{T} / \mathrm{T} / \mathrm{T}$ & $\mathrm{T} / \mathrm{T}$ & $\mathrm{T} / \mathrm{T} / \mathrm{T}$ & $\mathrm{T} / \mathrm{T}$ & $\mathrm{T} / \mathrm{T} / \mathrm{T}$ \\
\hline & Neurons/HL & 30 & $60 / 50$ & 58 & $48 / 52$ & 40 & $52 / 52$ & 60 & $50 / 26$ & 60 & $50 / 60$ & 40 & $26 / 28$ \\
\hline
\end{tabular}

Notation: T=Tansig, L=Logsig, HL=Hidden Layer

Due to the fact that the abovementioned differences between the maximum values of the OA index extracted by the networks with one or two hidden layers are not significant, a further examination of their performance using the other parameters which are defined through the CMs, is required. Thus, in Figure 8 the CMs of the optimum configured networks with one and two hidden layers which correspond to the testing sub-sets for the three versions of the selected RC buildings are presented.

\begin{tabular}{|c|c|c|c|c|c|c|c|c|c|c|c|c|c|c|c|}
\hline \multicolumn{4}{|c|}{ ANN's classification } & \multicolumn{4}{|c|}{ ANN's classification } & \multicolumn{4}{|c|}{ ANN's classification } & \multicolumn{4}{|c|}{ ANN's classification } \\
\hline \multirow{4}{*}{ 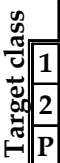 } & 1 & 2 & $\mathbf{R}$ & 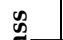 & 1 & 2 & $\mathbf{R}$ & 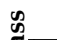 & 1 & 2 & $\mathbf{R}$ & $\mathscr{m}$ & 1 & 2 & $\mathbf{R}$ \\
\hline & 109 & 14 & $88.6 \%$ & 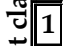 & 119 & 13 & $90.2 \%$ & $\sqrt[\widetilde{c}]{1}$ & 102 & 9 & $91.9 \%$ & ปี 1 & 110 & 15 & $88.0 \%$ \\
\hline & 6 & 22 & \begin{tabular}{|l||}
$78.6 \%$ \\
\end{tabular} & 2 & 7 & 12 & $63.2 \%$ & ơㅁ 2 & 7 & 33 & $82.5 \%$ & 2 & 2 & 24 & $92.3 \%$ \\
\hline & $94.8 \%$ & $61.1 \%$ & $86.8 \%$ & \begin{tabular}{l|l|l|}
- & $P$ \\
\end{tabular} & $94.4 \%$ & $48.0 \%$ & $86.8 \%$ & $\stackrel{\widetilde{\sim}}{\sim} \mid$ & $93.6 \%$ & $78.6 \%$ & $89.4 \%$ & $\stackrel{7}{-1} \mathbf{P}$ & $98.2 \%$ & $51.5 \%$ & $88.7 \%$ \\
\hline
\end{tabular}

(a)

\begin{tabular}{|c|c|c|c|c|c|c|c|c|c|c|c|c|c|c|c|}
\hline \multicolumn{4}{|c|}{ ANN's classification } & \multicolumn{4}{|c|}{ ANN's classification } & \multicolumn{4}{|c|}{ ANN's classification } & \multicolumn{4}{|c|}{ ANN's classification } \\
\hline & $\overline{1}$ & 2 & $\overline{\mathbf{R}}$ & क & $\overline{1}$ & 2 & $\overline{\mathbf{R}}$ & n & $\overline{1}$ & 2 & $\overline{\mathbf{R}}$ & y & $\overline{1}$ & 2 & $\overline{\mathbf{R}}$ \\
\hline$\overline{1}$ & 98 & 23 & $81.0 \%$ & $\tilde{\tau}$ & 88 & 23 & $79.3 \%$ & $\sqrt[3]{1}$ & 95 & 19 & $83.3 \%$ & $\sqrt[\widetilde{U}]{1}$ & 88 & 26 & $77.2 \%$ \\
\hline & 22 & 88 & $80.0 \%$ & & 26 & 94 & $78.3 \%$ & o 2 & 22 & 95 & $81.2 \%$ & 2 & 18 & 99 & $84.6 \%$ \\
\hline & $81.7 \%$ & $79.3 \%$ & $80.5 \%$ & $\stackrel{\pi}{-1}$ & \begin{tabular}{|l|l|}
$\mathbf{P}$ & $77.2 \%$ \\
\end{tabular} & $80.3 \%$ & $\mid 78.8 \%$ & $\tilde{\sim} \mid \mathbf{P}$ & $81.2 \%$ & $83.3 \%$ & $82.3 \%$ & $\stackrel{\widetilde{\sigma}}{-1} \mathbf{I}$ & $\begin{array}{l}\mathbf{P} 83.0 \% \\
\end{array}$ & $79.2 \%$ & $81.0 \%$ \\
\hline
\end{tabular}

(b)

\begin{tabular}{|c|c|c|c|c|c|c|c|c|c|c|c|c|c|c|c|}
\hline \multicolumn{4}{|c|}{ ANN's classification } & \multicolumn{4}{|c|}{ ANN's classification } & \multicolumn{4}{|c|}{ ANN's classification } & \multicolumn{4}{|c|}{ ANN's classification } \\
\hline & $\overline{1} 1$ & 2 & $\overline{\mathbf{R}}$ & in & $\overline{11}$ & 2 & $\overline{\mathrm{R}}$ & क & $\overline{1}$ & 2 & $\overline{\mathbf{R}}$ & m & $\overline{1}$ & 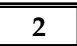 & $\overline{\mathbf{R}}$ \\
\hline 1 & 83 & 15 & $84.7 \%$ & $\sqrt[3]{1}$ & 69 & 13 & $84.1 \%$ & ปี 1 & 82 & 11 & $88.2 \%$ & $\sqrt[3]{1}$ & 72 & 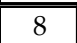 & $\mid 90.0^{\circ}$ \\
\hline 2 & 11 & 49 & $81.7 \%$ & 2 & 13 & 63 & $82.9 \%$ & 앤 2 & 8 & 57 & |87.7\% & 원 2 & 13 & 65 & $83.3 \%$ \\
\hline $\mathbf{P}$ & $88.3 \%$ & $\overline{60}$ & $83.5 \%$ & 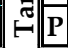 & $84.1 \%$ & $2.9 \%$ & $83.5 \%$ & 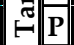 & $91.1 \%$ & $33.8 \%$ & $88.0 \%$ & 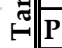 & $84.7 \%$ & $89.0 \%$ & $86.7 \%$ \\
\hline
\end{tabular}

(c)

Figure 8. CMs according to the testing sub-sets extracted by the optimum configured NA1 networks: (a) BB, (b) RIB, (c) IIB. 
From the study of Figure 8 it is obvious that the networks with two hidden layers are more efficient than the networks with one hidden layer, not only on the basis of the OA index values but also according to the other two indices which are defined in CMs, namely the Recall (R) index and the Precision (P) index. More specifically, the networks which are the most efficient according to OA index (Figure 7) have also, in general, higher values of R-index and P-index for the 3 versions of studied RC buildings (BB, RIB, IIB). This means that the optimum configured networks with two hidden layers classifies efficiently the studied samples in each one of the two SDC. Therefore, the high OA values of Figure 7 are extracted due to correct classifications to both the two pre-defined SDC and not to only one of them.

After the above presented study of the results extracted from the trained networks used for the solution of the problem according to A1, it can be concluded that the most efficient (optimum configured) networks on the basis of the testing sub-set are those which are summarized in Table 7.

Table 7. Configuration parameters and names of the optimum networks used for the approach A1

\begin{tabular}{rccc}
\hline Version of buildings & BB & RIB & IIB \\
\hline Training Algorithm & RP & RP & RP \\
Number of HL & 2 & 2 & 2 \\
Activation Functions & L/L/T & L/L/T & T/T/T \\
Neurons/HL & $36 / 34$ & $28 / 14$ & $20 / 10$ \\
Name of Network & NA1-BB & NA1-RIB & NA1-IIB \\
\hline
\end{tabular}

Notation: T=Tansig, L=Logsig, HL=Hidden Layer

4.2. Optimum configuration of the MLP networks used for the implementation of Approach A2

As it was mentioned above (and in Table 3) the A2 is defined using two alternative types which differ in the number of the pre-defined SDC for the buildings which are classified in SDC "S" for $\theta=0$ (categories C3S and C2S). On the contrary, only one category for classification of buildings which are classified in SDC " $M$ " for $\theta=0$ is defined (category C2M). Thus, in order to compare the two types of A2 (i.e. "A2/(C3S+C2M)" and "A2/(C2S+C2M)" in Table 3), a comparison between the categories C3S (Networks NA2C3S) and C2S (Networks NA2C2S) must be performed.

4.2.1. Comparative evaluation of the optimum configured NA2C3S and NA2C2S networks

In Figure 9 the OA index values extracted by the optimum configured networks NA2C3S and NA2C2S for the three versions of the selected RC buildings are presented.

From the study of Figure 9 the following main conclusions are extracted:

- In general, the C2S extract more reliable predictions than the C3S. This conclusion is valid for the three versions of RC buildings. However, the differences between the two categories is not significant especially in case of BB (maximum difference $2.44 \%$ ). For the other two versions of buildings the differences are greater but not significant (the maximum differences are $11 \%$ for RIB and $7.8 \%$ for IIB).

- According to the testing sub-sets, which are generally used in the current paper for the comparisons, no clear conclusion can be extracted as regards the most efficient training algorithm. In case of C3S the SCG algorithm is more efficient than the RP only for BB. On the contrary, in case of C2S the RP algorithm is more efficient than the SCG only for IIB.

- $\quad$ The addition of the second hidden layer improves the OA index values but no significantly as regards the comparisons using the testing sub-sets. For BB the differences of maximum OA index values between the networks with 1 and 2 hidden layers are $4.8 \%$ in case of C3S and $3.6 \%$ in case of C2S. For RIB the corresponding 
differences are $3.2 \%$ in case of $\mathrm{C} 3 \mathrm{~S}$ and $5.1 \%$ in case of C2S, whereas for IIB are $2.3 \%$ in case of $\mathrm{C} 3 \mathrm{~S}$ and $3.2 \%$ in case of $\mathrm{C} 2 \mathrm{~S}$.

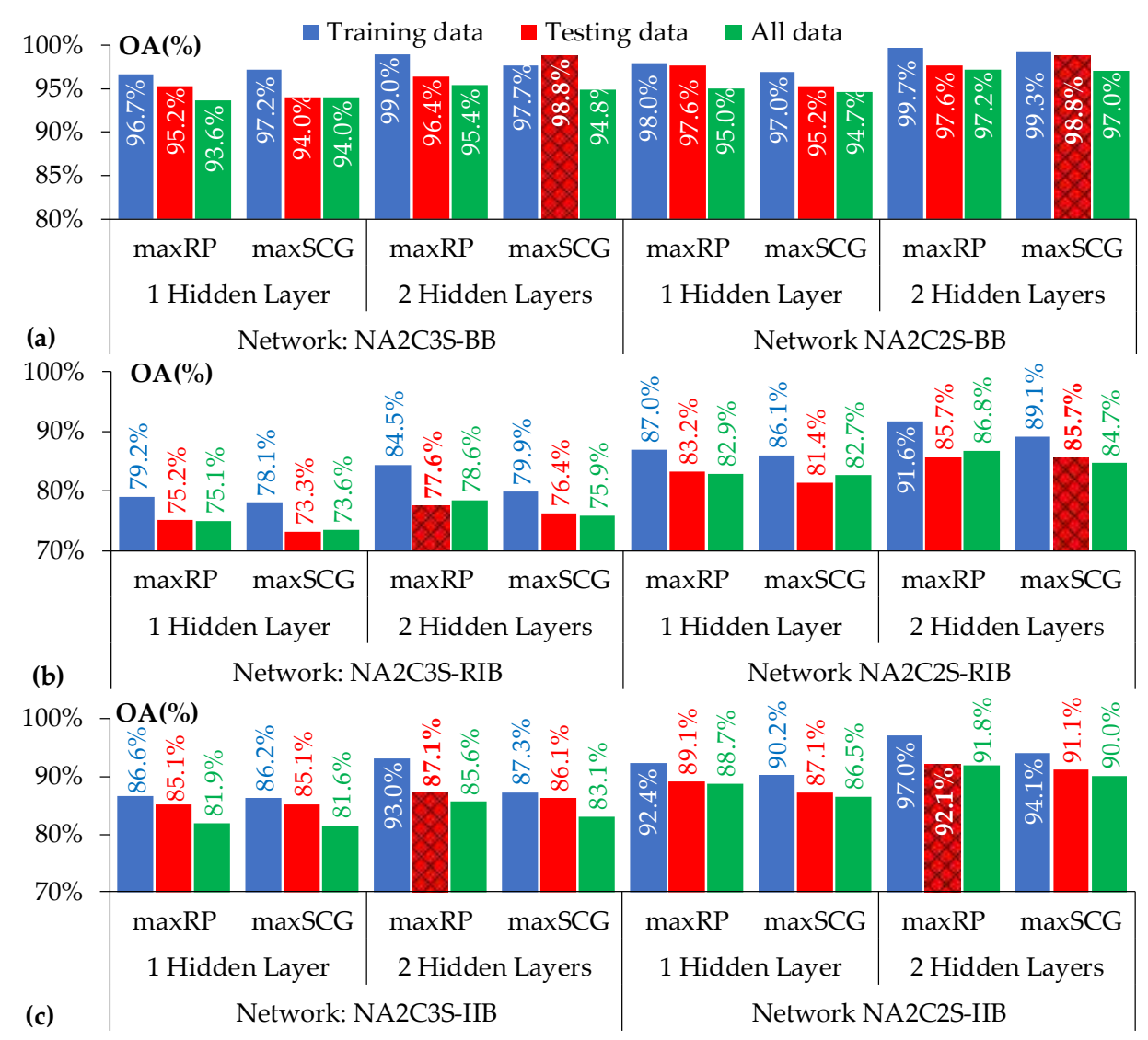

Figure 9. Maximum OA index values extracted by NA2C3S and NA2C2S networks with 1 or 2 hidden layers: (a) BB, (b) RIB, (c) IIB

The results of the above analysis lead to the requirement for additional evaluation using the other metrics which are defined in CMs for the extraction of a more robust conclusion as regards the most efficient category between C3S and C2S. Thus, in Figure 10, the CMs of the best configured networks of Figure 9 (i.e. the networks which extract the maximum OA index values presented in Figure 9) are illustrated.

The configurations of CMs of Figure 10, indicate that the performance of NA2C2S networks is generally very efficient regardless of the version of RC buildings (BB, RIB, IIB). Indeed, for all versions of buildings the values of the R-index and the P-index are greater than $75.8 \%$. In addition, the vast majority of the values of these indices are greater than $85 \%$. On the contrary, as regards the NA2C3S networks, the corresponding level of efficiency for all versions of RC buildings is not clear. In case of $B B$ the values of $R$ - and P-factors are extremely high but the configuration of the corresponding testing sub-set contains only samples which are classified to SDC "S" for $\theta=0$. Therefore, no conclusion can be extracted for the ability of the network to classify correctly the samples to other SDC. After an extended investigation for other configurations of testing sub-sets (it is reminded herein that in any training procedure the sub-sets are formed randomly) which contain all $\operatorname{SDC}(\theta=0)$ it was extracted that the corresponding OA was smaller than $98.8 \%$. Thus, in any case, the NA2C3S networks can not be characterized as more effective than the NA2C2S for BB. As regards the RIB is it obvious that the values of R-index and the P-index can not considered as acceptable. Finally, the same holds for the values of $\mathrm{R}$-index of CM of RIB. For the above-mentioned reasons, the C2S (networks NA2C2S) is obviously more efficient than the C3S (networks NA2C3S). 


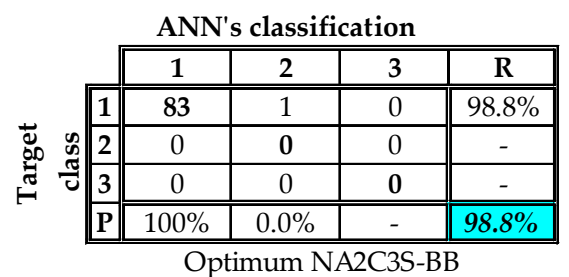

(a)

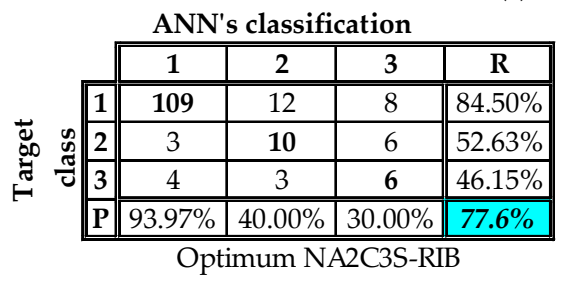

(b)

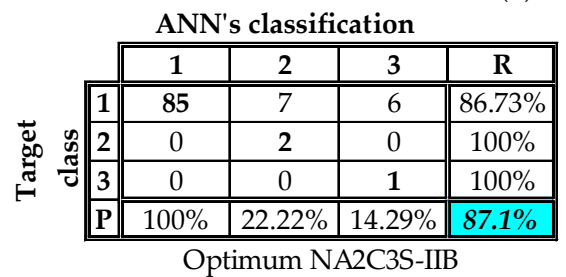

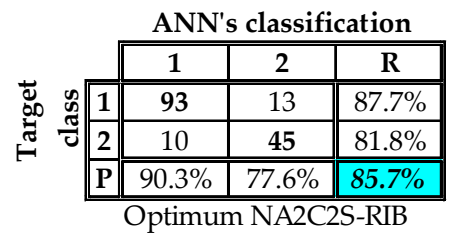

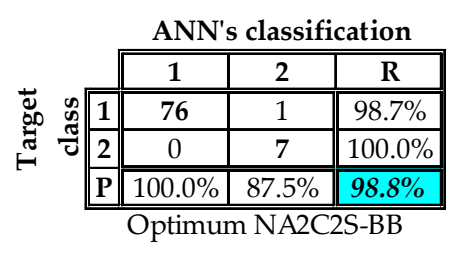

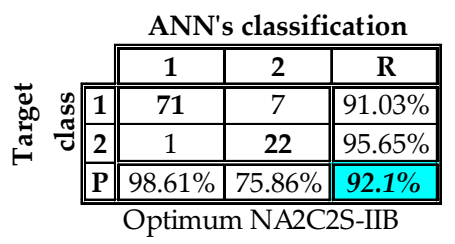

(c)

Figure 10. CMs according to the testing sub-sets extracted by the optimum configured NA2C3S and NA2C2S networks: (a) BB, (b) RIB, (c) IIB.

\subsubsection{Optimum configuration of the $\mathrm{NA} 2 \mathrm{C} 2 \mathrm{M}$ networks}

In the sub-section 4.2.1. it was proven that the NA2C2S optimum configured networks are more efficient than the NA2C3S ones. In the current section the results of the procedure for the investigation of the optimum configured NA2C2M network is presented.

In Figure 11 the OA index values extracted by the optimum configured NA2C2M networks for the three versions of the selected RC buildings are summarized. From the study of Figure 11 it can be concluded that, as in the above examined cases, the networks with two hidden layers extract higher OA values than the networks with one hidden layer. In addition, these OA values are higher than $90 \%$ for each one of the three versions of RC buildings. As regards the most efficient training algorithms no general conclusion can be extracted, since for the BB and RIB the SCG algorithm is more efficient than the RP algorithm, whereas for IIB the opposite is true. However, these differences between the OA values extracted using the two algorithms are no significant, especially for the testing sub-sets (less than $3.3 \%$ ). 


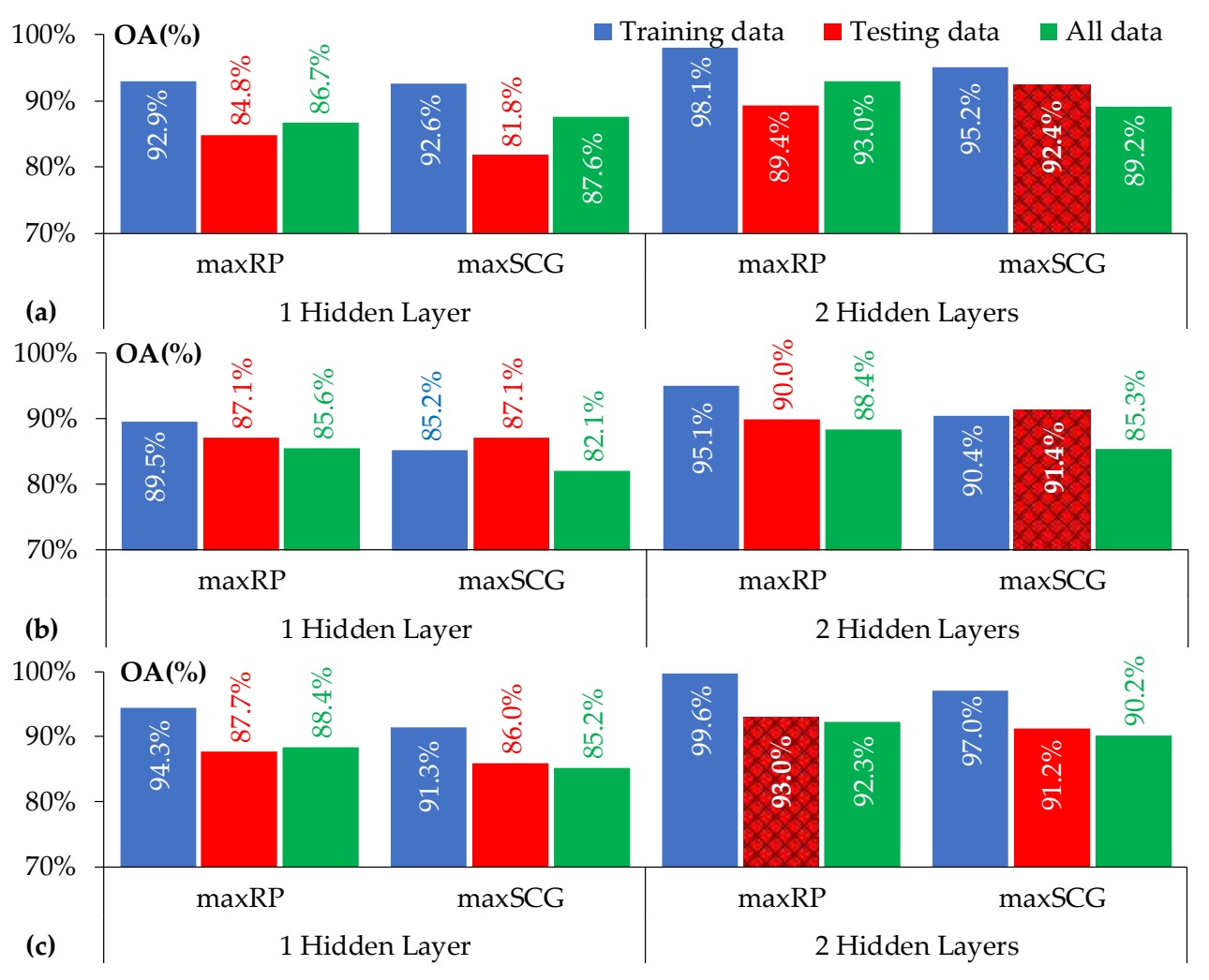

Figure 11. Maximum OA index values extracted by NA2C2M networks with 1 or 2 hidden layers: (a) BB, (b) RIB, (c) IIB

In order to confirm more robustly the advantage of networks with 2 hidden layers, the CMs which correspond to the optimum configured networks with 1 and 2 hidden layers (Figure 11) on the basis of the testing sub-sets, are presented in Figure 12.

\begin{tabular}{|c|c|c|c|c|c|c|c|c|c|c|c|c|c|c|c|}
\hline \multicolumn{4}{|c|}{ ANN's classification } & \multicolumn{4}{|c|}{ ANN's classification } & \multicolumn{4}{|c|}{ ANN's classification } & \multicolumn{4}{|c|}{ ANN's classification } \\
\hline \multirow{4}{*}{ 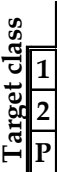 } & 1 & 2 & $\mathbf{R}$ & 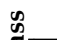 & 1 & 2 & $\mathbf{R}$ & $\infty$ & 1 & 2 & $\mathbf{R}$ & के & 1 & 2 & $\mathbf{R}$ \\
\hline & 33 & 6 & $84.6 \%$ & ป⿱一兀) 1 & 27 & 8 & $77.1 \%$ & ป⿱一兀] 1 & 29 & 2 & $93.5 \%$ & $\sqrt[\pi]{1}$ & 32 & 3 & $91.4 \%$ \\
\hline & 4 & 23 & $85.2 \%$ & 2 & 4 & 27 & $87.1 \%$ & 2 & 5 & 30 & $85.7 \%$ & 2 & 2 & 29 & $93.5 \%$ \\
\hline & $89.2 \%$ & $79.3 \%$ & $84.8 \%$ & $\tilde{F} P$ & $87.1 \%$ & $77.1 \%$ & $81.8 \%$ & $\stackrel{\tilde{\sim}}{-P} \mathbf{P}$ & $85.3 \%$ & $93.8 \%$ & $89.4 \%$ & $\stackrel{\tilde{F}}{ } \mathbf{P}$ & $94.1 \%$ & $90.6 \%$ & $92.4 \%$ \\
\hline
\end{tabular}

(a)

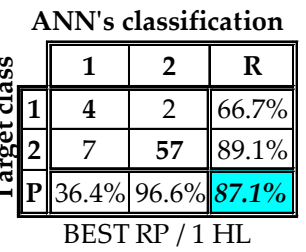

ANN's classification

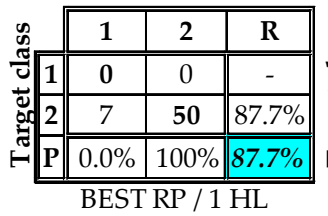

ANN's classification

\begin{tabular}{|c|c|c|c|}
\hline & 1 & 2 & $\mathbf{R}$ \\
\hline $\mid 1$ & 10 & 3 & 76.9 \\
\hline 2 & 6 & 51 & $89.5^{\circ}$ \\
\hline $\mathbf{P}$ & $62.5 \%$ & $94.4 \%$ & $87.1^{\circ}$ \\
\hline
\end{tabular}

(b)

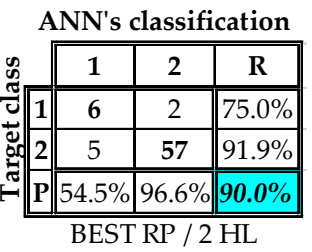

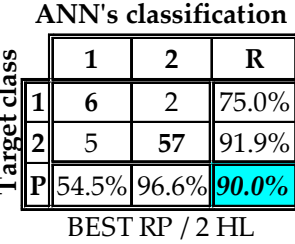

ANN's classification

\begin{tabular}{|c|c|c|c|}
\hline \multicolumn{4}{|c|}{ ANN's classification } \\
\hline & 1 & 2 & $\mathbf{R}$ \\
\hline 1 & 0 & 0 & - \\
\hline 2 & 8 & 49 & $86.0 \%$ \\
\hline $\mathbf{P}$ & $0.0 \%$ & $100 \%$ & $86.0 \%$ \\
\hline
\end{tabular}

(c)

\begin{tabular}{|c|c|c|c|}
\hline क & 1 & 2 & $\mathbf{R}$ \\
\hline$\sqrt[8]{1}$ & $\bar{~} 15$ & $\bar{~} 1$ & 93.8\% \\
\hline$\approx 2$ & 3 & 38 & $92.7 \%$ \\
\hline$P$ & $83.3^{\circ}$ & $97.4^{\circ}$ & $93.0 \%$ \\
\hline
\end{tabular}

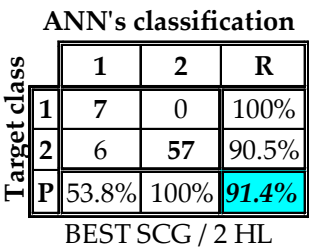

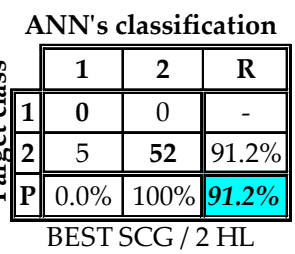

Figure 12. CMs according to the testing sub-sets extracted by the optimum configured NA2C2M networks: (a) BB, (b) RIB, (c) IIB. 
The study of Figure 12 confirms (on the basis of R-index and the P-index) the conclusion that the networks with 2 hidden layers are more efficient than the networks with 1 hidden layer. Indeed, the vast majority of the R-index and R-index values of CMs which correspond to networks with 2 hidden layers are greater than $90 \%$. On the contrary, the vast majority of the corresponding values of the CMs of networks with 1 hidden layer are lower than $90 \%$.

Closing the presentation of the results of the investigation for the optimum configuration of MLP networks used for the implementation of the approach A2, the parameters of the optimum configured NA2C3S, NA2C2S and NA2C2M networks are summarized in Table 8.

Table 8. Configuration parameters and names of the optimum networks used for the implementation of the approach A2

\begin{tabular}{|c|c|c|c|c|c|c|c|c|c|}
\hline \multirow{2}{*}{$\begin{array}{c}\text { Category } \\
\text { Version of } \\
\text { buildings }\end{array}$} & \multicolumn{3}{|c|}{ A2/C3S } & \multicolumn{3}{|c|}{$\mathrm{A} 2 / \mathrm{C} 2 \mathrm{~S}$} & \multicolumn{3}{|c|}{$\mathrm{A} 2 / \mathrm{C} 2 \mathrm{M}$} \\
\hline & BB & RIB & IIB & BB & RIB & IIB & BB & RIB & IIB \\
\hline $\begin{array}{l}\text { Training } \\
\text { Algorithm }\end{array}$ & SCG & $\mathrm{RP}$ & $\mathrm{RP}$ & SCG & SCG & $\mathrm{RP}$ & SCG & SCG & $\mathrm{RP}$ \\
\hline $\begin{array}{r}\text { Number of } \\
\text { HL }\end{array}$ & 2 & 2 & 2 & 2 & 2 & 2 & 2 & 2 & 2 \\
\hline $\begin{array}{l}\text { Activation } \\
\text { Functions }\end{array}$ & $\mathrm{T} / \mathrm{L} / \mathrm{L}$ & $\mathrm{L} / \mathrm{L} / \mathrm{T}$ & $\mathrm{L} / \mathrm{L} / \mathrm{T}$ & $\mathrm{T} / \mathrm{T} / \mathrm{T}$ & $\mathrm{T} / \mathrm{L} / \mathrm{T}$ & $\mathrm{L} / \mathrm{T} / \mathrm{T}$ & $\mathrm{L} / \mathrm{T} / \mathrm{T}$ & $\mathrm{T} / \mathrm{T} / \mathrm{T}$ & $\mathrm{T} / \mathrm{T} / \mathrm{T}$ \\
\hline Neurons/HL & $30 / 50$ & $16 / 52$ & $44 / 26$ & $36 / 46$ & $50 / 36$ & $46 / 16$ & $56 / 38$ & $48 / 22$ & $20 / 24$ \\
\hline $\begin{array}{l}\text { Name of } \\
\text { Network }\end{array}$ & $\begin{array}{c}\text { NA2C3S- } \\
\text { BB }\end{array}$ & $\begin{array}{c}\text { NA2C3S- } \\
\text { RIB }\end{array}$ & $\begin{array}{c}\text { NA2C3S-I } \\
\text { IB }\end{array}$ & $\begin{array}{c}\text { NA2C2S- } \\
\text { BB }\end{array}$ & $\begin{array}{c}\text { NA2C2S- } \\
\text { RIB }\end{array}$ & $\begin{array}{c}\text { NA2C2S-I } \\
\text { IB }\end{array}$ & $\begin{array}{c}\text { NA2C2M- } \\
\text { BB }\end{array}$ & $\begin{array}{c}\text { NA2C2M- } \\
\text { RIB }\end{array}$ & $\begin{array}{c}\text { NA2C2M- } \\
\text { IIB }\end{array}$ \\
\hline
\end{tabular}

4.3. Comparison of the efficiency of the optimum configured networks for Approaches A1 and A2

In this sub-section the results of the comparison between the optimum configured networks used for the implementation of the Approaches A1 and A2 are presented and evaluated. More specifically, the networks described in Table 7 (Approach A1) and Table 8 (Approach A2) are compared using the percentages of the correct classifications (OA index values) which are extracted for the samples of the testing sub-sets. It is reminded here that as regards the Approach A2 the type "A2/(C2S+C2M)" is more efficient than the type "A2/(C3S+C2M)" as it was proven in sub-section 4.2. Therefore, the results extracted by the networks NA1-BB, NA1-RIB and NA1-IIB (Table 7) are compared to those extracted by the networks NA2C2S-BB/NA2C2M-BB, NA2C2S-RIB/NA2C2M-RIB and NA2C2S-IIB/NA2C2M-IIB (Table 8) respectively. Thus, in Figure 13 the OA values which are extracted by the abovementioned networks are summarized.

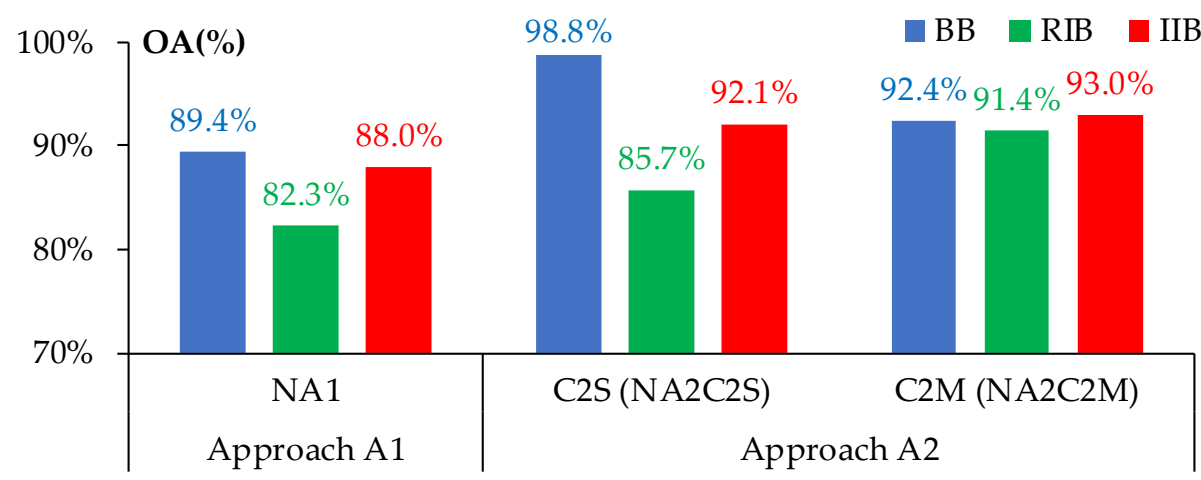

Figure 13. OA values extracted by the optimum configured networks of Approaches A1 and A2 
The results presented in Figure 13 indicate that the Approach A2 is clearly more efficient than the Approach A1 according to the OA index values for each one of the three versions of the selected RC buildings. However, the efficiency of the Approach A1 is not unacceptable, since the OA index of the corresponding classifications is greater than $82 \%$ for RIB, whereas is close to $90 \%$ for BB and IIB. Definitely, the vast majority of the OA values extracted by means of Approach A2 is greater than 90\%, but it must be reminded that the implementation of A2 requires the knowledge of the classification of buildings to an SDC for $\theta=0$. This means that NTHA or the simulation of properly trained MLP networks are required for this classification (NӨ0 networks in Figure 3(b)).

\begin{tabular}{|c|c|c|c|c|}
\hline \multirow{5}{*}{\multicolumn{2}{|c|}{ 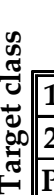 }} & & & \\
\hline & & 1 & 2 & $\overline{\bar{R}}$ \\
\hline & & 102 & 9 & $91.9 \%$ \\
\hline & 2 & 7 & 33 & $82.5 \%$ \\
\hline & $\mathbf{P}$ & $93.6 \%$ & $78.6 \%$ & $\mid 89.4 \%$ \\
\hline
\end{tabular}

\begin{tabular}{|c|c|c|c|}
\hline \multirow{2}{*}{ 总 } & \multicolumn{3}{|c|}{ ANN's classification } \\
\hline & $\overline{11}$ & 2 & $\overline{\mathrm{R}}$ \\
\hline 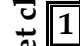 & $\overline{76}$ & $\overline{1} 1$ & $98.7 \%$ \\
\hline 2 & 0 & 7 & $100 \%$ \\
\hline $\mathbf{P}$ & $100 \%$ & $87.5 \%$ & $98.8 \%$ \\
\hline
\end{tabular}

\begin{tabular}{|c|c|c|c|}
\hline \multirow{5}{*}{ 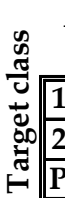 } & \multicolumn{3}{|c|}{ ANN's classification } \\
\hline & $\overline{11}$ & $\overline{2}$ & $\overline{\bar{R}}$ \\
\hline & 32 & $\overline{3}$ & $91.4 \%$ \\
\hline & 2 & 29 & $93.5 \%$ \\
\hline & $94.1 \%$ & $90.6 \%$ & $92.4 \%$ \\
\hline
\end{tabular}

ANN's classification

\begin{tabular}{|c|c|c|c|c|}
\hline & & $\overline{1}$ & 2 & $\overline{\mathbf{R}}$ \\
\hline & 1 & 95 & $\overline{19}$ & $83.3 \%$ \\
\hline & 2 & 22 & 95 & $81.2 \%$ \\
\hline & $\mathbf{P}$ & $81.2 \%$ & $83.3 \%$ & $82.3 \%$ \\
\hline
\end{tabular}

(a)

\begin{tabular}{|c|c|c|c|}
\hline & \multicolumn{3}{|c|}{ ANN's classification } \\
\hline & $\overline{1}$ & 2 & $\overline{\mathbf{R}}$ \\
\hline 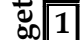 & 93 & 13 & $87.7 \%$ \\
\hline ב 2 & 10 & 45 & $81.8 \%$ \\
\hline $\mathbf{P}$ & $90.3 \%$ & $77.6 \%$ & $85.7 \%$ \\
\hline
\end{tabular}

ANN's classification

\begin{tabular}{|c|c|c|c|}
\hline & $\overline{1}$ & 2 & $\overline{\bar{R}}$ \\
\hline 1 & $\overline{77}$ & 0 & $\mid 100 \%$ \\
\hline 2 & 6 & 57 & $90.5 \%$ \\
\hline $\mathbf{P}$ & $53.8 \%$ & $100 \%$ & $91.4 \%$ \\
\hline
\end{tabular}

(b)

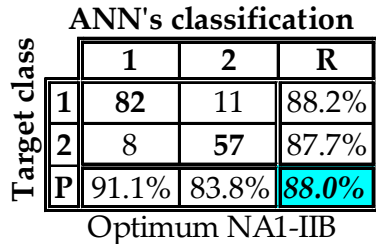

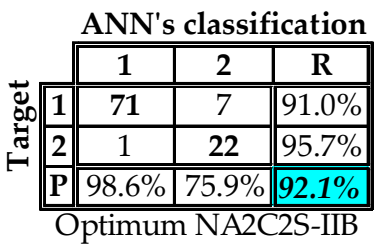

\begin{tabular}{|c|c|c|c|}
\hline \multirow{5}{*}{ 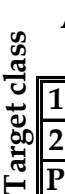 } & \multicolumn{3}{|c|}{ ANN's classification } \\
\hline & $\overline{1}$ & 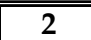 & $\overline{\bar{R}}$ \\
\hline & $\overline{15}$ & $\overline{1}$ & $93.8 \%$ \\
\hline & 3 & 38 & $92.7 \%$ \\
\hline & $83.3 \%$ & $97.4 \%$ & $93.0 \%$ \\
\hline
\end{tabular}

Figure 14. CMs extracted by the optimum configured networks of Approaches (a) A1 and (b) A2

Therefore, the implementation of A2 is accompanied by an additional classification for the studied buildings. This additional classification can possibly add errors to the entire procedure. On the other hand, the Approach A1 is free of these errors and is more flexible, because it can be implemented regardless of the existence or no of classification of buildings for $\theta=0$.

Finally, the conclusion regarding the higher efficiency of the Approach A2 is also confirmed by means of the CMs (i.e. the corresponding values of R-index and P-index) which are summarized in Figure 14.

\section{Conclusions}

In the current paper the ability of the Multilayered Feedforward Perceptron (MLP) networks to reliably predict in real time the influence of the critical angle of seismic excitation $\theta_{\mathrm{cr}}$ on the seismic damage of RC buildings is studied. To this end, the problem was defined and solved as a Pattern Recognition (PR) problem. Thus, three different Seismic Damage Classes (SDC) were defined ("Slight" or "S", "Moderate" or " $\mathrm{M}$ " and "Heavy" or " $\mathrm{H}$ ") on the basis of the Maximum Interstorey Drift Ratio (MIDR), which is a widely used seismic damage index. Two different Approaches for the definition of the PR problem were considered. The first one (Approach 1 or A1) is a two-class PR problem where the one class corresponds to buildings for which the SDC for $\theta=0$ is not increased for $\theta=\theta_{\text {cr }}\left\{\right.$ Class 1: $\operatorname{SDC}\left(\theta=\theta_{\text {cr }}=\operatorname{SDC}(\theta=0)\right\}$, whereas the second class corresponds to the opposite condition $\left\{\right.$ Class 2: $\left.\operatorname{SDC}\left(\theta=\theta_{\mathrm{cr}}\right)>\operatorname{SDC}(\theta=0)\right\}$. The second one (Approach 2 or $\mathrm{A} 2$ ) is based on the initial separation of buildings in two categories, namely the buildings 
which are classified to " $S$ " SDC for $\theta=0$ and those which are classified to " $M$ " SDC for $\theta=0$. Then, two different categories of A2 are defined: in the framework of the first one (A2/C3S) three classes are considered for the buildings which are classified to "S" SDC for $\quad \theta=0 \quad\left\{\right.$ Class $\quad 1$ : $\quad \operatorname{SDC}(\theta=0)=" S^{\prime \prime} \rightarrow \operatorname{SDC}\left(\theta=\theta_{\mathrm{cr}}\right)=" \mathrm{~S}^{\prime \prime}, \quad$ Class 2: $\operatorname{SDC}(\theta=0)={ }^{\prime \prime} S^{\prime \prime} \rightarrow \operatorname{SDC}\left(\theta=\theta_{\mathrm{cr}}\right)={ }^{\prime \prime} \mathrm{M}^{\prime \prime}$, Class 3: $\left.\operatorname{SDC}(\theta=0)={ }^{\prime \prime} \mathrm{S}^{\prime \prime} \rightarrow \operatorname{SDC}\left(\theta=\theta_{\mathrm{cr}}\right)={ }^{\prime \prime} \mathrm{H}^{\prime \prime}\right\}$, whereas in the framework of the second one $(\mathrm{A} 2 / \mathrm{C} 2 \mathrm{~S})$ two classes for these buildings are defined $\left\{\right.$ Class 1: $\operatorname{SDC}(\theta=0)={ }^{\prime \prime} S^{\prime \prime} \rightarrow \operatorname{SDC}\left(\theta=\theta_{\mathrm{cr}}\right)={ }^{\prime \prime} S^{\prime \prime}$, Class 2: $\operatorname{SDC}(\theta=0)={ }^{\prime \prime} S^{\prime \prime} \rightarrow \operatorname{SDC}\left(\theta=\theta_{\mathrm{cr}}\right)={ }^{\prime \prime} \mathrm{M}^{\prime \prime}$ or " $\left.\mathrm{H}^{\prime \prime}\right\}$. On the other hand, two classes for the buildings which are classified to "M" SDC for $\theta=0$ (category $\mathrm{A} 2 / \mathrm{C} 2 \mathrm{M}$ ) are considered in any case \{Class 1: $\operatorname{SDC}(\theta=0)={ }^{\prime \prime} \mathrm{M}^{\prime \prime} \rightarrow \operatorname{SDC}\left(\theta=\theta_{\mathrm{cr}}\right)={ }^{\prime} \mathrm{M}^{\prime \prime}$, Class 2: $\left.\operatorname{SDC}(\theta=0)={ }^{\prime \prime} \mathrm{M}^{\prime \prime} \rightarrow \operatorname{SDC}\left(\theta=\theta_{\mathrm{cr}}\right)={ }^{\prime \prime} \mathrm{H}^{\prime \prime}\right\}$. Thus, two analysis types were defined in the framework of A2: "A2/(C3S+C2M)" and "A2/(C2S+C2M)", whereas one analysis type was defined in the framework of A1 (the analysis type "A1").

For each one of the above-mentioned analysis types one category (four in total) of MLP networks (NA1 networks for "A1", NA2C3S networks for "A2/C3S", NA2C2S networks for "A2/C2S" and NA2C2M networks for "A2/C2M") was configured and trained using training data-sets which were generated by the authors in previous published research papers on the basis of three different versions of 30 properly selected RC buildings (Bare Buildings "BB", Regularly Infilled Buildings "RIB", and Irregularly Infilled Buildings "IIB"). As regards the input vectors for the MLP networks, twelve widely used seismic parameters and three structural parameters were used. Due to the fact that the scope of the current research is the study of the influence of the critical angle of seismic excitation on the seismic damage, the $\mathrm{min} / \mathrm{max}$ ratios of the values of the selected seismic parameters which correspond to the two recorded horizontal components of excitations, instead of the values which are extracted using a numerical combination of them, were used. As regards the three structural parameters, the selection of them was also based on the nature of the problem, as well as on general (and macroscopic) indices which influence the seismic damage response of buildings. Extended parametric investigation for the detection of the optimum configuration of each one of the four categories of the MLP networks was performed. In this investigation the number of hidden layers, the number of neurons in each hidden layer, the type of activation functions of neurons and the training algorithms were examined. Thus, this parametric investigation led to the optimum configured network of each one of the four categories. The performance of the studied configurations was evaluated using the Overall Accuracy (OA) index. In cases in which this index fails to lead to clear conclusions the other metrics which are defined in the framework of the Confusion Matrices (CM), i.e. the R-index and the P-index were additionally used. The evaluation of networks was based in any case on the testing sub-sets which are the parts of the data-sets used for the investigation of their generalization ability.

The main conclusions which were extracted from the above described research procedure are the following:

- Between the two different categories of the Approach A2 for the buildings which are classified to SDC " $\mathrm{S}$ " for $\theta=0$, the "A2/C2S" was proven more efficient than the "A2/C3S" for all versions of the studied RC buildings (BB, RIB, IIB). This conclusion was based on comparisons of the values of OA-index as well as on comparisons of the values of the $\mathrm{R}$ - and P-index. The superiority of the "A2/C2S" against the "A2/C3S" means that the trained networks in the present study are more efficient for correct classifications in PR problems with two categories. This conclusion (which certainly cannot be characterized as conclusion generally valid) must be further examined in a future extended research. However, the low efficiency of the trained networks used in the current study to classify the testing samples to correct SDC eliminates the possibility of reliable predictions about the specific SDC of buildings for $\theta=\theta$ cr. Therefore, the reliable predictions concern the information about the change (or not change) of the SDC for $\theta=\theta_{\text {cr. }}$ Thus, the category "A2/C2S" in com- 
bination with the category "A2/C2M" (which corresponds to buildings which are classified to SDC " $\mathrm{M}$ " for $\theta=0)$, i.e. the analysis type "A2/(C2S+C2M)", was used for the comparison of Approach A2 with the Approach A1.

- The Approach A2, expressed in the form of analysis type "A2/(C2S+C2M)", was proven as more efficient than the Approach A1. However, the percentages of the correct classifications extracted by A1 cannot be characterized as unacceptable, since the corresponding OA values are in any case greater than $80 \%$. On the other hand, the OA values extracted by " $\mathrm{A} 2 /(\mathrm{C} 2 \mathrm{~S}+\mathrm{C} 2 \mathrm{M})$ " are greater than $90 \%$. The real difference between the two Approaches can be reduced since the application of A2 requires the knowledge of the SDC of buildings for $\theta=0$. This knowledge can be obtained either by implementation of NTHA either by the simulation of networks properly trained to predict the SDC of buildings for $\theta=0$. In both cases the possibility of the insertion of errors can lead to incorrect data for the implementation of "A2/(C2S+C2M)". On the contrary, the Approach A1 can be implemented without the knowledge of the SDC of buildings for $\theta=0$. Thus, the A1 is not affected by these additional errors. For this reason, the two Approaches can be generally characterized as almost equal.

- As regards the optimum configuration of networks it was observed that the addition of a second hidden layer improves their classification ability in all studied cases. However, the increases of OA index values which are achieved using two hidden layers instead of one are not always significant. On the contrary, the addition of the second hidden layer significantly increases the values of R- and P-index in all cases. The optimum number of neurons in hidden layers can not be estimated without the implementation of parametric investigation using a pre-defined rule. This conclusion is consistent with the findings of the available relative literature. The Resilient Backpropagation (RP) algorithm was proven as more effective in the training of NA1 networks (approach A1). On the contrary, no clear conclusion can be extracted for the analysis types of approach A2 because the RP algorithm and the Scaled Conjugate Gradient (SCG) algorithm (which was also used in the present study) were proven to be more effective in almost the same number of cases which belong to this approach. Finally, it was proven that the introduction of the hyperbolic tangent (Tansig) function as the activation function of neurons of the output layer of networks leads to optimum classifications in all analyses which use the approach $\mathrm{A} 1$, and in the vast majority of analyses which use the approach A2.

Finally, it must be noted that a future expansion of the current investigation can include the examination of different seismic or/and structural parameters for the input vectors of networks, sensitivity analyses for the estimation of the parameters which mostly influence the proposed method's efficiency and the prediction of the value of the critical angle of the seismic excitation using the MLP networks (or other type of networks) as calculational tools for regression analysis.

\section{References}

1. MacRae, G.A.; Mattheis, J. Three dimensional steel building response to near-fault motions. J Struct Eng - ASCE 2000, 126(1), 117-26.

2. Athanatopoulou, A.M. Critical orientation of three correlated seismic components. Eng Struct 2005, 27, 301-12.

3. Rigato, A.B.; Medina, R.A. Influence of angle of incidence on seismic demands for inelastic single-storey structures subjected to bi-directional ground motions. Engineering Structures 2007, 29(10), 2593-2601.

4. Kostinakis, K.; Athanatopoulou, A.; Avramidis, I. Orientation effects of horizontal seismic components on longitudinal reinforcement in R/C frame elements. Nat. Hazards Earth Syst. 2012, 12, 1-10.

5. Kostinakis, K.G.; A.M. Athanatopoulou, A.M.; Tsiggelis V.S. Effectiveness of percentage combination rules for maximum response calculation within the context of linear time history analysis. Engineering Structures 2013, 56, 36-45.

6. Kostinakis, K.; Morfidis K.; Xenidis H. Damage response of multistorey r/c buildings with different structural systems subjected to seismic motion of arbitrary orientation. Earthquake Engineering and Structural Dynamics 2015, 44(12), $1919-1937$.

7. Kostinakis, K.; Manoukas, G.; Athanatopoulou, A. Influence of seismic incident angle on response of symmetric in plan buildings. KSCE Journal of Civil Engineering 2018, 22:2, 725-735. 
8. Fontara, I-K.; Kostinakis, K.; Manoukas, G.; Athanatopoulou, A. Parameters affecting the seismic response of buildings under bi-directional excitation. Structural Engineering and Mechanics 2015, 53(5), 957-979.

9. Pavel, F.; Nica, G. Influence of Rotating Strong Ground Motions on the Response of Doubly Symmetrical RC Wall Structures in Romania and Its Implication on Code Provisions. International Journal of Civil Engineering 2019, 17(7), 969-979.

10. Cavdar, E.; Ozdemir, G. Using maximum direction of a ground motion in a code-compliant analysis of seismically isolated structures. Structures 2020, 28, 2163-2173.

11. Lagaros, N.D. The impact of the earthquake incident angle on the seismic loss estimation. Engineering Structures 2010, 32(6), 1577-1589.

12. Giannopoulos, D.; Vamvatsikos, D. Ground motion records for seismic performance assessment: To rotate or not to rotate? Earthquake Engineering and Structural Dynamics 2018, 47(12), 2410-2425.

13. Vargas Alzate, Y.F.; Pujades Beneit, L.G.; Barbat, A.H.; Hurtado Gomez J.E.; Diaz Alvarado, S.A.; Hidalgo Leiva, D.A. Probabilistic seismic damage assessment of reinforced concrete buildings considering directionality effects. Structure and Infrastructure Engineering 2018, 14(6), 817 - 829.

14. Skoulidou, D.; Romao, X.; Franchin, P. How is collapse risk of RC buildings affected by the angle of seismic incidence. Earthquake Engineering and Structural Dynamics 2019, 48(14), 1575-1594.

15. Skoulidou, D.; Romão, X. The significance of considering multiple angles of seismic incidence for estimating engineering demand parameters. Bulletin of Earthquake Engineering 2020, 18(1), 139-163.

16. EN1998-1 (Eurocode 8-1). Design of structures for earthquake resistance - part 1: general rules, seismic actions and rules for buildings. European Committee for Standardization, 2005.

17. Adeli, H. Neural networks in civil engineering: 1989-2001. Comput Aid Civ Infrastruct Eng 2001, 16, 126-42.

18. Shahin, M.A.; Jaksa, M.B.; Maier, H.R. State of the art of artificial neural networks in geotechnical engineering. Electr J Geotech Eng EJGE 2008, 8, 1-26.

19. Jegadesh, S.J.S.; Jayalekshmi, S. A review on artificial neural network concepts in structural engineering applications. Int J Appl Civ Env Eng 2015, 1(4), 6-11.

20. Sun, H.; Burton, H.V.; Huang, H. Machine learning applications for building structural design and performance assessment: State - of - the - art review. Journal of Building Engineering 2021 33, Article 101816.

21. Harirchian, E.; Hosseini, S.E.A.; Jadhav, K.; Kumari, V.; Rasulzade, S.; Işık, E.; Wasif, M.; Lahmer, T. A review on application of soft computing techniques for the rapid visual safety evaluation and damage classification of existing buildings. Journal of Building Engineering 2021, 43, Article 102536.

22. Stephens, J.E.; VanLuchene, R.D. Integrated Assessment of Seismic Damage in Structures. Microcomput Civ Eng 1994, 9, 119-128.

23. Molas, G.; Yamazaki, F. Neural networks for quick earthquake damage estimation. Earthquake Eng Struct Dyn 1995, 24, 505-16.

24. De Stefano, A.; Sabia, D.; Sabia L. Probabilistic neural networks for seismic damage mechanisms prediction. Earthquake Engineering and Structural Dynamics 1999; 28, 807-821.

25. Sanchez-Silva, M.; Garcia, L. Earthquake damage assessment based on fuzzy logic and neural networks. Earthquake Spectra 2001, 17(1), 89-112.

26. Lagaros, N.; Fragiadakis, M. Fragility Assessment of Steel Frames Using Neural Networks. Earthquake Spectra 2007, 23(4), 735-752.

27. Gonzalez, M.P.; Zapico, J.L. Seismic damage identification in buildings using neural network and modal data. Computers and Structures 2008, 86, 416-426.

28. Lautour, O.R.; Omenzetter, P. Prediction of seismic-induced structural damage using artificial neural networks. Engineering Structures 2009, 31, 600-606.

29. Arslan, M.H. An evaluation of effective design parameters on earthquake performance of RC buildings using neural networks. Engineering Structures 2010, 32(7), 1888-1898.

30. Vafaei, M.; Adnan, A.B.; Rahman, A.B.A. Real-time seismic damage detection of concrete shear walls using artificial neural networks. J Earthquake Eng 2013, 17, 137-54.

31. Morfidis, K.; Kostinakis, K. Seismic parameters' combinations for the optimum prediction of the damage state of R/C buildings using neural networks. Advances in Engineering Software 2017, 106, 1-16.

32. Morfidis, K.; Kostinakis, K. Approaches to the rapid seismic damage prediction of r/c buildings using artificial neural networks. Eng Struct 2018, 165, 120-141.

33. Morfidis, K.; Kostinakis, K. Comparative evaluation of MFP and RBF neural networks' ability for instant estimation of r/c buildings' seismic damage level. Eng Struct 2019, 197, 1-19.

34. Theodoridis, S.; Koutroumbas, K. Pattern Recognition, 4th ed.; Elsevier, 2008.

35. Naeim, F. The seismic design handbook, 2nd ed; Springer, 2001.

36. Gunturi, S.K.V.; Shah, H.C. Building specific damage estimation. Proceedings of 10th world conference on earthquake engineering. Madrid, Spain, 19-24 July 1992, 6001-6.

37. Beyer, K.; Bommer, J. Selection and Scaling of Real Accelerograms for Bi-Directional Loading: A Review of Current Practice and Code Provisions. J. Earthq Eng 2007, 11, 13-45.

38. EN1998-2 (Eurocode 8-2). Design of structures for earthquake resistance - part 2: Bridges. European Committee for Standardization, 2005. 
39. FEMA 356. Pre-standard and commentary for the seismic rehabilitation of buildings. Federal Emergency Management Agency, Washington D.C., 2000.

40. ASCE 41-06. Seismic Rehabilitation of Existing Buildings. American Society of Civil Engineers, Reston, Virginia, 2009.

41. ASCE 41-13. Seismic Evaluation and Retrofit of Existing Buildings. American Society of Civil Engineers, Reston, Virginia, 2014.

42. NZS 1170.5. Structural design actions, Part 5: Earthquake actions - New Zealand, Code and Supplement, Standards New Zealand, Wellington, New Zealand, 2004.

43. Lucchini, A.; Monti, G.; Kunnath, S. Nonlinear Response of Two-Way Asymmetric Single-Story Building under Biaxial Excitation. Journal of Structural Engineering, ASCE 2011, 137(1), 34-40.

44. Nguyen, V.T.; Kim, D. Influence of incident angles of earthquakes on inelastic responses of asymmetric-plan structures. Structural Engineering and Mechanics 2013, 45(3), 373-389.

45. Roy, A.; Santra, A.; Roy, R. Estimating seismic response under bi-directional shaking per uni-directional analysis: Identification of preferred angle of incidence. Soil Dynamics and Earthquake Engineering 2018, 106, 163-181.

46. Bishop, C.M. Pattern Recognition and Machine Learning, Springer, 2006.

47. Kappos, A.J. Seismic damage indices for RC buildings: evaluation of concepts and procedures. Construction Research Communications (Limited ISSN 1365-0556) 1997, 78-87.

48. Masi, A.; Vona, M.; Mucciarelli, M. Selection of natural and synthetic accelerograms for seismic vulnerability studies on reinforced concrete frames. J Struct Eng 2011, 137, 367-78.

49. EN1992-1-1 (Eurocode 2-1-1). Design of concrete structures, Part 1-1: General rules and rules for buildings. European Committee for Standardization, 2005.

50. Caglar, N.; Garip, Z.S. Neural network based model for seismic assessment of existing RC buildings. Comput Concr 2013, 12(2), $1-18$.

51. Kia, A.; Sensoy, S. Assessment the Effective Ground Motion Parameters on Seismic Performance of R/C Buildings using Artificial Neural Network. Indian Journal of Science and Technology 2014, 7(12), 2076-2082.

52. Kramer, S.L. Geotechnical earthquake engineering, Prentice-Hall, 1996.

53. Beyer, K.; Bommer, J. Relationships between median values and between aleatory variabilities for different definitions of the horizontal component of motion. Bull Seismol Soc Am 2006, 96(4A), 1512-22.

54. Haykin, S. Neural networks and learning machines, 3rd ed.; Prentice Hall, 2009.

55. Fawcett, T. An introduction to ROC analysis. Pattern Recognition Letters 2006, 27, 861-874.

56. Caruana, R.; Lawrence, S.; Giles, L. Overfitting in neural nets: backpropagation, conjugate gradient, and early stopping. Proceedings of neural information processing systems, Denver, Colorado, USA, 2000, 402-8.

57. X, Ying. An Overview of Overfitting and its Solutions. Journal of Physics: Conference Series 2019, 1168(2). doi: 10.1088/1742-6596/1168/2/022022.

58. Riedmiller, M.; Braun, H. A Direct Adaptive Method for Faster Backpropagation Learning: The RPROP Algorithm. Proceedings of IEEE, San Francisco 1993, 586-591.

59. Moller, M.F. A scaled conjugate gradient algorithm for fast supervised learning. Neural Networks 1993, 6(4), 525-33 